\title{
Novel possibility for cutaneous melanoma treatment by means of rosmarinic acid action on purinergic signaling
}

\author{
Gilnei Bruno da Silva ${ }^{1} \cdot$ Milena Ayumi Yamauchi $^{1} \cdot$ Daniela Zanini ${ }^{1} \cdot$ Margarete Dulce Bagatini ${ }^{1}$ (I)
}

Received: 6 May 2021 / Accepted: 12 October 2021 / Published online: 5 November 2021

(c) The Author(s), under exclusive licence to Springer Nature B.V. 2021

\begin{abstract}
Cancer cases have increased significantly in Brazil and worldwide, with cutaneous melanoma (CM) being responsible for nearly 57,000 deaths in the world. Thus, this review article aims at exploring and proposed hypotheses with respect to the possibility that RA can be a promising and alternative compound to be used as an adjuvant in melanoma treatment, acting on purinergic signaling. The scarcity of articles evidencing the action of this compound in this signaling pathway requires further studies. Considering diverse evidence found in the literature, we hypothesize that RA can be an effective candidate for the treatment of $\mathrm{CM}$ acting as a modulating molecule of purinergic cellular pathway through $\mathrm{P} 2 \mathrm{X} 7$ blocking, mitigating the Warburg effect, and as antagonic molecule of the P2Y12 receptor, reducing the formation of adhesive molecules that prevent adherence in tumor cells. In this way, our proposals for CM treatment based on targeting purinergic signaling permeate the integral practice, going from intracell to extracell. Undoubtedly, much is still to be discovered and elucidated about this promising compound, this paper being an interesting work baseline to support more research studies.
\end{abstract}

Keywords Cancer · Purinergic system · Phenolic compound · Melanoma. Rosmarinic acid · Chemotherapy

\section{Introduction}

Globally, 1 out of 5 individuals develops cancer during their lifetime, which suggests that more than 50 million people are living 5 years after a cancer diagnosis, the cutaneous melanoma (CM) type being responsible for nearly 57,000 deaths in the world [1]. In addition, this is one of the most

Highlights

- Novel agents need to be researched in melanoma treatment as alternatives to conservative therapies;

- This review sought to find relationships between RA and its properties on $\mathrm{CM}$;

- Diverse evidence suggests that RA can be a promising phenolic compound adjuvant to treat melanoma through cell signaling pathway modulation;

- Hypothetically, RA can modulate the purinergic system by blocking P2X7R and acts as an ADP-inducing antagonist in P2Y12R;

- It seems that this compound has the ability to induce apoptosis on the melanoma cell type.

Margarete Dulce Bagatini

margaretebagatini@yahoo.com.br

1 Graduate Program in Biomedical Sciences, Universidade Federal da Fronteira Sul, Fronteira Sul, Chapecó, SC 89815-899, Brazil aggressive types among the cutaneous tumors due to its highly metastatic and low survival rates [2].

In Brazil, skin cancer has presented expressive growth in the last years, corresponding to $27 \%$ of all the malignant tumors, and $\mathrm{CM}$ is responsible for 8400 new cases per year, with more incidence in the South of the country [3, 4]. This increased number of cases has been linked to excessive sunbathing, due to harms by ultraviolet (UV) radiation [5].

To treat this disease, drugs that lead to unwanted side effects are used; in addition, none shows efficient mechanisms to avoid lethal progression of the pathology [6]. Biochemical therapy has been indicated as a promising adjuvant strategic management [7], but the development of new options is crucial so that there is a rise in patients' survival [8].

Thus, many research science teams are looking for the best melanoma treatment; in other words, one with few or no side effects, in addition to low pharmacologic resistance during the therapeutic path. An interesting alternative to this would be to use natural substances, such as phenolic compounds that can have anticancer effects, either associated with conventional pharmacology or in isolation, as long as there is scientific support. 
An essential signaling pathway recently related to tumor cell progression is the purinergic system, which interferes with mechanisms such as disordered cell proliferation, promotion of angiogenesis, and failure of mechanisms controlling apoptosis. This is due to an imbalance in the concentrations of adenosine triphosphate (ATP), adenosine diphosphate (ADP), and adenosine monophosphate (AMP) nucleotides and of adenosine (Ado), and nucleoside present in the tumor environment (TME), as well as overexpression or, in some cases, low expression of $\mathrm{P} 2$ receptors and ectonucleotidases [9-11]

To corroborate the aforementioned conjectures, a large number of in vitro and in vivo studies have indicated the potential of phenolic compounds, especially caffeic acid (CA) and rosmarinic acid (RA), as antioxidant, antiproliferative, anticancerogenic, and antitumor agents, as well as modulators of cell pathways and biochemical cascades [12-17]. Furthermore, some studies have suggested the ability of RA to modulate the purinergic system [18].

It is important to highlight that, up to the present day, few works involving RA with $\mathrm{CM}$ can be found in the scientific literature, and the same happens with the purinergic system, which reinforces the need for research on this theme. Therefore, this review article aims at exploring and proposed hypotheses with respect to the possibility that RA can be a promising and alternative compound to be used as an adjuvant in melanoma treatment, acting on purinergic signaling, since it seems to have antitumor, antiangiogenic, and antiproliferative effects, as well as involved in cell pathway signaling. To such end, based on other research studies with different cancer contexts where RA, chemical characteristics of phenolic compounds and purinergic signaling modulatory molecule effects, we hypothesized two possible mechanisms through which the purinergic system can be the RA target in the pharmacological therapeutic perspective for CM.

\section{Cutaneous melanoma}

The skin is the largest organ of the human body and covers its entire external surface, where it has an important function in the protection against toxic agents, friction, injuries, and radiation. In addition to that, it is divided into the epidermis, the outermost layer, and the dermis, the deeper stratum, constituted of conjunctive tissue. On the epidermis, there are keratinocytes, melanocytes, Langerhans cells, and Merkel cells [19]. CM is one of the malignant pathologies that affects the epidermis, being characterized as a cytological disorder that affects melanocytes, which produce melanin, increasing the proliferative ability of these cells due to a series of changes in the cell cycle and in the apoptosis mechanisms. CM is an oncological pathology characterized by the high invasiveness of tumor cells, and has a high metastatic capacity, causing a short survival period and high mortality rates $[2,8]$.

In the epidemiologic context of this disease, in a study published by Enninga et al. [20], 201,719 diagnoses of cutaneous melanoma were made between 1992 and 2011 in the world. Among those, survival rate was better in women, and the hypothesis was the difference in behavior and human biology. However, when analyzing the disease stage, there is no difference between the genders in the mortality rate, revealing that the female advantage is restricted to a localized and regional disease. Despite this, the survival rate is better when there is an early diagnosis in both genders.

By the year 2020, the incidence of CM in the world, including both genders and all ages, was 324,635 new cases and more than 57,000 deaths, mostly affecting North America, Europe, and Oceania. In Brazil, this type of cancer, which recorded 8624 new cases last year, is the $20^{\text {th }}$ most frequent in the country. Looking at the future, the estimate for 2030 is a $15.8 \%$ increase of new cases worldwide [1]. Estimates for 2020 in Brazil were 4200 new cases for men and 4250 for women, more frequently in the South of the country [21], and, despite CM is not the most prevalent type of cancer, it is responsible for more than $75 \%$ of the deaths due to skin cancer, being considered a major public health problem [22].

As in other solid tumors, the staging of CM is based on the tumor, nodes, and metastasis (TNM) classification, where "T" refers to the size of the primary tumor, "N" refers to the invasion or not of the lymph nodes, and "M" refers to the presence of distant metastases. Below, we present Table 1 referring to the staging of $\mathrm{CM}$, as well as to fundamental criteria to define the therapeutic of action that will be chosen for the treatment of this malignant pathology [23].

Considering the malignancy of CM, early and correct diagnosis is very important for a successful treatment. However, this can be difficult because of its variability in cytomorphology and its similarity to benign lesions [24, 25]. At first, there are four main types of CM, according to their histological and growth characteristics, namely: superficial spreading, nodular melanoma, lentigo maligna, and acral lentiginous. Most of them remain in the epidermis, growing horizontally, known as the radial growth phase, while in the vertical growth phase, infiltration occurs in the dermis, conferring metastatic potential to it [25].

As already mentioned, diagnosis must be careful, since $\mathrm{CM}$ can manifest in various clinicopathologic forms [24-26]. Nevertheless, the gold standard for diagnosis is histopathological analysis associated with clinical recognition. In the latter, it is important to pay attention to the patient's history and risk factors and to perform a skin examination of the entire body being able to count on the assistance of dermoscopy. Subsequently, the ABCDE rule must be applied to each lesion, in addition to the "ugly 
Table 1 Melanoma TNM classification

\begin{tabular}{|c|c|c|}
\hline Tumor (T) & Breslow thickness (mm) & Ulceration/mitotic rate \\
\hline Tis & Not applicable & Not applicable \\
\hline T1 & $\leq 1.0 \mathrm{~mm}$ & $\begin{array}{l}\text { a: no ulceration } /<1 \mathrm{~mm}^{2} \\
\text { b: ulceration } / \geq 1 \mathrm{~mm}^{2}\end{array}$ \\
\hline $\mathbf{T 2}$ & $1.01-2.0 \mathrm{~mm}$ & $\begin{array}{l}\text { a: no ulceration } \\
\text { b: ulceration }\end{array}$ \\
\hline T3 & $2.01-4.0 \mathrm{~mm}$ & $\begin{array}{l}\text { a: no ulceration } \\
\text { b: ulceration }\end{array}$ \\
\hline T4 & $>4.0 \mathrm{~mm}$ & $\begin{array}{l}\text { a: no ulceration } \\
\text { b: ulceration }\end{array}$ \\
\hline Node $(\mathbf{N})$ & Number of metastatic nodes & Nodal metastatic mass \\
\hline No & 0 & Not applicable \\
\hline N1 & 1 & $\begin{array}{l}\text { a: micrometastasis } \\
\text { b: macrometastasis }\end{array}$ \\
\hline $\mathbf{N 2}$ & $2-3$ & $\begin{array}{l}\text { a: micrometastasis } \\
\text { b: macrometastasis } \\
\text { c: in-transit metastasis/satel- } \\
\text { lites and no nodes }\end{array}$ \\
\hline $\mathbf{N 3}$ & $\begin{array}{l}\geq 4 \text { metastatic nodes or in-transit metasta- } \\
\text { ses/satellite(s) } \\
\text { with metastatic node(s) }\end{array}$ & \\
\hline Metastasis (M) & Site & Lactate dehydrogenase value \\
\hline Mo & No distant metastases & Not applicable \\
\hline M1a & $\begin{array}{l}\text { Distant skin, subcutaneous or nodal } \\
\text { metastases }\end{array}$ & Normal \\
\hline M1b & Lung metastases & Normal \\
\hline M1c & $\begin{array}{l}\text { All other visceral metastases } \\
\text { Any distant metastasis }\end{array}$ & $\begin{array}{l}\text { Normal } \\
\text { Elevated }\end{array}$ \\
\hline
\end{tabular}

Source: Adapted from Gershenwald and Scolyer [174] duckling" sign so that a nevus different from the others, in the same individual, is followed more carefully (Table 2). Furthermore, imaging techniques can be supported for early diagnosis, such as dermoscopy and diagnosis confirmation; skin biopsy is the most useful [27, 28].

It is known that the main risk factor for melanoma development is exposure to UV radiation, which is present in sunlight. In addition, there are three types of UV radiation: UVA, UVB, and UVC, although the latter is blocked by the ozone layer, while UVA and UVB reach the Earth; and exposure to these types can cause DNA damage and consequent development of melanoma. Although UVA is the most emitted radiation (90-95\%), UVB is more prone to cause burns and skin harms [29, 30].

Ultimately, some research evidence shows that other risk factors can exert an influence on the incidence of melanoma. At first, risk is greater for women in the first decades of life, while men are more prone when they reach adult life. In addition, even if having more female diagnoses at the beginning, prognosis is better, but it is not the same as people age $[29,31]$.
Another associated risk factor is skin color because, in dark and hair, eumelanin is most abundant, a type of melanin which is synthesized under the $\alpha$-melanocyte-stimulating hormone $(\alpha-\mathrm{MSH})$ signaling to a melanocortin-1 receptor (MC1R), while individuals with red hair and freckles have more pheomelanin due to loss-of-function mutation in MC1R that prevents eumelanin production. Thus, eumelanin reduces the UV-induced harms, unlike pheomelanin, which contributes to the formation of free radicals and, consequently, to DNA damage [30]. Therefore, according to Rastrelli et al. [32], individuals with fair skin, freckles, and red hair are more predisposed to melanoma by approximately $50 \%$, as is the number of melanocytic nevi, family history, and genetic susceptibility.

Among the possible pathological factors of cancer, oxidative stress connected with inflammation and the purinergic system is frequently cited. Oxidative stress is a process caused by an imbalance between the production of free radicals and metabolic reactions mediated by the action of antioxidants, whose function is to inhibit or reduce the lesion from an excess of these reactive products. Reactive oxygen species (ROS) are 
Table 2 Explanation of the $\mathrm{ABCDE}$ rule on $\mathrm{CM}$ diagnosis. Source: Adapted from Michielin et al. [23]

\begin{tabular}{|c|c|c|}
\hline SYMBOL & MEANING & REPRESENTATION \\
\hline A - Asymmetry & Peripherals outside of the lesion are not equal. & \\
\hline $\begin{array}{l}\text { B - Border } \\
\text { irregularity }\end{array}$ & Uneven border of the lesion. & \\
\hline $\begin{array}{l}\mathrm{C} \text { - Color } \\
\text { variation }\end{array}$ & Multiple colors throughout the lesion. & \\
\hline D - Diameter & Diameter larger than $6 \mathrm{~mm}$. & \\
\hline E - Evolution & Change in shape, color and size throughout time. & \\
\hline
\end{tabular}

free radical products mainly generated by the mitochondria, during cellular respiration resulting in a reduction of $\mathrm{O}_{2}$, and are in abundance in the inflammatory process, in addition to other cells of the immune system and cell proliferation factors, and, for this reason, there is an uncontrolled increase in the amount of free radicals, which results in an oxidative stress field [33-36].

A literature review corroborates that oxidative stress is involved in the initiation of carcinogenesis in many ways, such as modification in energy metabolism, imbalance between antioxidants and oxidants, and nonspecific chronic inflammation activation with excessive production of pro-inflammatory cytokines, triggering ROS increase [37]. Oxidative stress can also modify the DNA structure and could contribute to tumor onset through environmental pollutants, as UV radiation does to $\mathrm{CM}$ [36].

\section{Hallmarks of cancer: the Warburg effect}

Around the 2000s, researchers Douglas Hanahan and Robert A. Weinberg published the article entitled "Hallmarks of cancer" in the renowned Cell Journal, bringing several impacts in the Oncology science worldwide. Attribution of the word "hallmarks" to cancer means that there are 6 characteristics common to tumors which are different from normal cells. Later, in 2011, these researches amplified the hallmarks and re-published updating in relation to it in the same journal the article entitled "Hallmarks of cancer: The next generation," now complementing the previous 6 with 4 new hallmarks. This conceptualization continues to be important nowadays [38, 39]. 
Therefore, the first hallmarks proposed were sustaining proliferative signaling, evading growth suppressors, resisting cell death, enabling replicative immortality, inducing angiogenesis, and activating invasion and metastasis. The last 4 included deregulation cellular energetics (reprogramming cellular metabolism), immune evasion, tumor promotinginflammation, and genome instability and mutation [38, 39].

Among the aforementioned, one of the new hallmarks, reprogramming cellular metabolism, curiously deserves to be highlighted due to its interference ability in other tumor parameters and hallmarks of cancer. In uncontrolled proliferation of tumors, there is a reprogrammed metabolic profile, with dramatically increased rate of glucose uptake and lactate production even in the presence of oxygen and fully functioning mitochondria, a phenomenon known as the Warburg effect (also called aerobic glycolysis) [38, 40, 41].

Most of the tumors present metabolic dependence on the Warburg effect and this condition is related with the promotion of cancer cell invasiveness, aggressiveness, and drug resistance [42-44]. Specifically on CM, although it has been associated with the glycolytic phenotype, recent studies have indicated that the metabolic phenotype nature of this pathology seems to go further, having dynamic plasticity [45-48].

Diverse evidence suggests that the immune cells' response in the TME contributes to cancer cell survival and growth [49]. Interestingly, this abnormal metabolic profile has been pointed out as one of the factors which support immune evasion to tumor cells and promote tumor progression [50-53]. What justified this fact is that, as cytoplasmic is produced, lactate is released in the extracellular microenvironment by monocarboxylate transporters (MCTs), leading to $\mathrm{pH}$ reduction and to TME acidification [54, 55]. Lactate is associated with inhibition of T-cell proliferation and alters cytokine production, as well as induces apoptosis of natural killer (NK) cells [56, 57]. Lactate also promotes cell suppression, both from innate and adaptive immunity, preventing maturation of dendritic cells (DCs) and favoring differentiation of regulatory $\mathrm{T}$ cells [58].

In addition to acting in immune mechanisms, the Warburg effect can interfere in gene expression and in respiratory function, such as increased expression of glucose transporter, hexokinase, and pyruvate kinase muscle (PKM2), modification in the expression of phosphoglycerate mutase (PGAM) that allows pyruvate production without ATP generation, increase in the pyruvate dehydrogenase kinase (PDK) levels, expression of specific transcription factors, mainly myelocytomatosis viral oncogene (MYC), hypoxiainducible factor 1 alpha (HIF-1 $\alpha$ ), nuclear factor kappalight-chain-enhancer of activated B cells $(\mathrm{NF}-\kappa \mathrm{B})$, and organic cation transporter 1 (OCT1) that sustain this effect [59].

Taking into consideration the strong evidence suggesting that the Warburg effect interferes in tumoral dynamics, such as supporting immune evasion, angiogenesis, or another mechanism, the inhibition of this tumor cell pathway seems to be one of the cancer targets in therapeutic perspectives, even against $\mathrm{CM}$.

\section{Main current therapeutic strategies for melanoma treatment}

The early stages of melanoma can be surgically treated by tissue resection. Despite that, in advanced stages such as metastatic cases, it used to be considered untreatable, given its high therapeutic resistance rate. With therapeutic strategies aimed at the immune system and with relative efficacy approved by the Food and Drug Administration (FDA), this value has significantly improved. However, the 5-year survival rate of patients with metastatic melanoma is still very low, approximately $23 \%$ [22], and 15 to $20 \%$ of the tumors are resistant to conventional treatment in their first attempt [60].

This is because melanoma cells have several striking characteristics that boost their resistance, including high genetic instability that continuously promotes transient mutations, including mutations in mitogen-activated protein kinase (MEK), neuroblastoma viral oncogene homolog (NRAS), and that circumvent murine viral sarcoma inhibitor $\mathrm{v}$-Raf oncogene homolog B1 (BRAF). Furthermore, its transduction network is highly effective in reconfiguring signals to prevent cell death. Similarly, melanoma cells mimic the stroma, promoting the development of growth factors and cytokines, among other mechanisms that favor TME [22].

Until 2011, conventional treatment was based on the use of chemotherapeutic agents that caused damage to cellular DNA, such as dacarbazine, leading to apoptosis. However, the drug's effectiveness in increasing the survival rate was not significant and the search for new alternatives found a new way out in immunotherapy and targeted therapies. In this context, monoclonal antibodies and BRAF and MEK inhibitors have become targets of several studies, with the aim of controlling immune responses [61, 62].

Ipilimumab, an anti-CTLA-4 antibody, and nivolumab and pembrolizumab, two anti-PD-1 and PD-L1 antibodies, were the immunological checkpoint inhibitors used in a literature review study by Namikawa and Yamazaki in 2019 [63], who showed greater efficacy when compared to the conventional treatment. They therefore concluded that the first line of choice for the treatment of the most advanced melanomas currently approved consists of three options, namely: nivolumab or pembrolizumab monotherapy or association of nivolumab with ipilimumab, and the choice is due to the melanoma subtypes [62,63].

However, the use of ipilimumab is limited, as its response rate is approximately $11 \%$ and it has several 
immunological side effects in organs, as it promotes exacerbation of normal and tumor cytotoxic T cells [64]. Furthermore, although anti-PD-1 and PD-L1 monoclonal antibodies exert a more satisfactory antitumor immune response (between 30 and 40\%), not all patients are sensitive to them, which requires another treatment alternative [65].

Targeted therapy with the BRAF inhibitor is due to the fact that this gene is mutated in more than $50 \%$ of the cutaneous melanoma cases, the result of which is an alteration in the BRAF protein that assists in the accelerated growth of cancer cells $[66,67]$. In the same signaling pathway, MEK gene inhibitors also reduce BRAF gene mutations and currently constitute the care standard in combination with BRAF inhibitors. This is because the progression-free survival of the isolated use of vemurafenib (inhibitor BRAF) allows for the development of melanoma resistance, while the association of another inhibitor verifies greater efficacy. The use of these combination therapies is approved by the FDA and includes vemurafenib/cobimetinib; dabrafenib/tramatenib; and encorafenib/binimetinib, the first being BRAF inhibitors and the second being MEK inhibitors [67, 68].

Although this combination prolongs survival and is the first choice for symptomatic patients with high tumor burden, acquisition of resistance is still a limiting factor for the development of an effective therapy [68]. Another limitation is the fact that this treatment does not cover $100 \%$ of the cutaneous melanomas, as it is not effective for those that do not present any BRAF gene mutation [67]. When compared to immunotherapy, targeted therapy offers a faster response and, clinically, the combination of both ends up being a treatment option [68].

Due to all these limitations pointed out, it is necessary to search for new therapeutic strategies in order to fully approach the patient and improve the prognosis. Furthermore, resistance to treatment is one of the main challenges to be overcome, as well as the side effects observed in immunotherapy [69]. In the medical, biomedical, and pre-clinical research studies, the cell lines are extremely important, such as animal cell culturing, since they provide almost all the genetic properties of cancer. In addition, apart from these cells derived from an in vivo sample, the environmental differences between the microenvironments such as the oxygen percentage and the tumor's interactions with other cells can change the results of the studies. However, the cell line, handled in an in vitro model, allows for the study of pathological features and for the application of new theories that cannot be carried out in vivo, especially as a preclinical model of a therapeutic view and, for this reason, widely used in cancer and drug research studies [70,71].

\section{Purinergic system: a brief characterization}

The purinergic system is a signaling cell pathway present in basically all body tissues, composed by extracell molecules of nucleotides and nucleosides, receptors and enzymes (ectoenzymes), which participate in physiologic and pathologic mechanisms of the human organism, such as cell proliferation, differentiation, and death, as well as immunomodulation [72-75]. A recent study hypothesized on the potential role of the purinergic system on therapy in cardiovascular diseases mediated by SARS-CoV-2 [76].

Initially, when a review study about purinergic signaling was published by Geoffrey Burnstock, currently considered the father of the purinergic system, the hypothesis was not well accepted in the academic world, possibly because of the consolidated theory involving ATP molecules in energetic biochemistry into cells. However, now it is clear that this molecule, as well as other nucleotides, also acts as an extracell messenger in diverse biological effects [77, 78].

Among the purinergic system compounds, ATP, ADP, and AMP nucleotides stand out, as well as Ado nucleoside, which performs the role of signaling molecules. ATP deserves to be highlighted and is the focus of several research studies, due to diverse evidence indicating that this biomolecule acts in the cell metabolism process, as inducement of DNA synthesis in timocitus, suppression of NKs, chemotaxis, and tumor destruction [79, 80].

Thus, the cell receptors for the aforementioned molecules are classified as purinoceptor $\mathrm{P} 1$, which is mediated by Ado, and as purinoceptor P2, selective for ATP and/or ADP. The P1 receptors are separated into four subtypes: $\mathrm{A} 1, \mathrm{~A} 2 \mathrm{~A}, \mathrm{~A} 2 \mathrm{~B}$, and $\mathrm{A} 3$, and the $\mathrm{P} 2$ into two subfamilies: P2Y, G-protein-coupled, and P2X, which are ligandgated ion channels (see Fig. 1). Currently, eight types of $\mathrm{P} 2 \mathrm{Y}$ receptors have been identified (P2Y1, P2Y2, P2Y4, P2Y6, P2Y11, P2Y12, P2Y13, and P2Y14), as well as seven types of P2X receptors (P2X1, P2X2, P2X3, P2X4, P2X5, P2X6, and P2X7) [81-83].

In addition, in purinergic signaling, there are enzyme structures involved that are coupled extracells in membranes, known as ectonucleotidases, them being ectonucleoside triphosphate diphosphohydrolase (E-NTPDases-CD39), ectonucleotide pyrophosphatase/ phosphodiesterase (E-NPPS), alkaline phosphatase, ecto5'-nucleotidase (5'-NT-CD73), and adenosine deaminase (ADA). All these enzymes play a role in the breakdown of ATP (see Fig. 1), which was previously described, and can generate their derivatives proceeding the initiation of the cascade with E-NTPDase action, which catalyzes the hydrolysis of ATP and ADP to AMP. Subsequently, 


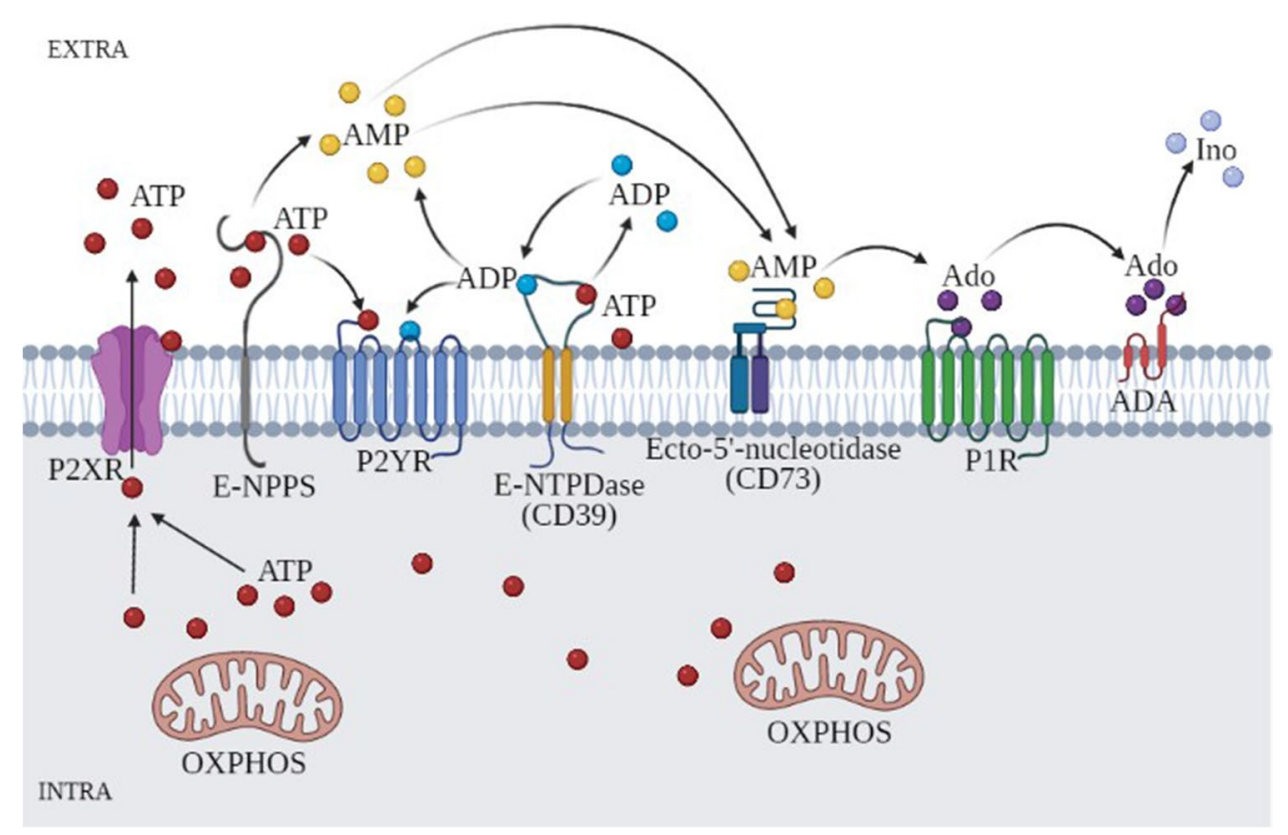

Fig. 1 Structures and functioning of the purinergic system. Initially, adenosine triphosphate (ATP), a key molecule of the purinergic system, is mainly generated intracellularly via oxidative phosphorylation (OXPHOS) in the mitochondria and can be released to the extracellular microenvironment by $\mathrm{P} 2 \mathrm{X}$ type receptors ( $\mathrm{P} 2 \mathrm{XR})$, such as $\mathrm{P} 2 \mathrm{X} 7$. Once outside, it is available to act as cell signaling in $\mathrm{P} 2 \mathrm{XR}$ and P2YR or to be hydrolyzed by ectonucleotidases to other nucleotides, such as adenosine monophosphate (AMP), adenosine diphosphate (ADP), and nucleosides, such as Adenosine (Ado). Only P1

ecto-5'-nucleotidase catalyzes the transformation of AMP into adenosine and, finally, is deaminated through ADA, resulting in inosine. It can also be possible that E-NPPS promotes hydrolysis of ATP directly to AMP and continue the cascade until the end [84, 85].

Thus, the purinergic signaling system seems to be involved with the health and disease process, such as in different tumors, and the role of this cell pathway has been extensively studied [86]. Knowing this, in comparison with normal cells, tumor cells have a large amount of ATP, depletion of this nucleotide being a strategy to activate anticancer pathways. In addition, P2 receptors are observed in many cancer types and can present inhibitory effects preventing cell proliferation, interfering in cell cycle, and promoting cell death. However, this depends on the subtype of receptor, as cancer cells can have more death sensitivity or resistance [87].

As already pointed out, each receptor of the purinergic system has a specific and different action that depends on several factors, such as cell type. Therefore, in the context of ATP receptors, despite being frequently associated with anticancer effects, as far as $\mathrm{P} 2 \mathrm{Y} 1$ and $\mathrm{P} 2 \mathrm{Y} 2$ are concerned, there are hypotheses shown on the TME that they support cell growth and proliferation [87, 88]. This can be type receptors (P1R) have affinity to Ado. Pyrophosphatase/phosphodiesterase (E-NPPS) has affinity to break down ATP straight to AMP, whereas ectonucleoside triphosphate diphosphohydrolase (E-NTPDase-CD39) can breakdown ATP to ADP or ADP to AMP. The only ectoenzyme capable of hydrolyzing AMP to Ado is ecto-5'nucleotidase (E-5'-NT-CD73). Finally, adenosine deaminase (ADA), the finisher of the purinergic cascade, can break down Ado to inosine (Ino)

corroborated with the paper by Joo et al. [89], in which they observed the action of these receptors promoting niche metastatic formation on breast cancer.

It is worth highlighting that the formation of extracell adenosine can mostly occur from the activity of the CD39 and CD73 enzymes, both in healthy and neoplastic tissues, although other pathways are involved, such as E-NPP action from AMP hydrolysis, CD73 being a major generator of this molecule. Some studies have shown an increase in the expression of those enzymes in different cancer contexts [90-93].

For confirmation purposes, many researches work to report that purinergic signaling is related to neoplasms, such as in lung cancer [94, 95], leukemia [96], CM [86, 97], pancreatic cancer [98], osteosarcoma [99], and gastric cancer [100].

It is evident that much remains to be elucidated about the purinergic system, considering from its discovery to the present day; in addition, this cell signaling system is more consolidated as widespread on the human organism [101], which can be indicated as a therapeutic target. In reference to cancer, the interest in research is growing, only because of that considerable possibility [87]. 


\section{Purinergic signaling in melanoma}

As is well known, the purinergic system is involved in cancer dynamics, with the possibility of participating, according to the many factors, as a tumor promoter or inhibitor. This occurs by means of signaling molecules' action, mainly ATP, ADP, AMP, and Ado, on cell-receptors and through the ectonucleotidases' activity in TME. It is important to emphasize that this cell pathway has a close relationship with the immune response in the cancer context, as in other situations, and, considering the entire purinergic chain, the levels of purinergic molecules are controlled by a complex network of nucleotide/nucleosideectonucleotidases, expressed on the cells' surface. In addition to that, ATP is a pivotal molecule which largely influences immune responses in peripheral and central tissues [102-105], can be released from the inflammatory and tumor cells via different mechanisms, such as exocytosis, plasma membrane channels, or lysis, and can be accumulated in TME $[92,106]$.

In melanoma cells, a high concentration of ATP can have an anticancer effect because it activates the P2X7 type receptors, leading to cell death [107]. Despite that, when ATP is hydrolyzed to ADP, it can present an immunosuppression effect on CM [97]. On the other hand, Ado, a product of ATP hydrolysis that mediates the protective response, such as immunosuppressive and anti-inflammatory effects on healthy tissues, seems to have a pro-carcinogenic property, such as stimulus of tumor growth and angiogenesis on CM-affected cell, in addition to higher cell mobility and metastasis; in other words, when interacting with P1 receptors, a high concentration of Ado acts effectively in tumor progression [11, 50, 61, 108].

Mânica et al. [109] found significant data about the role of ATP in melanoma patients, indicating that an increased inflammatory process by extracellular ATP leads to an immunosuppressive profile even after CM surgical removal; and the purinergic system can develop a chronic inflammatory microenvironment which can exert a direct influence on relapse or metastasis. This effect involves deregulation of nucleotide and nucleoside levels in peripheral blood.

Other outstanding purinergic receptors involved in melanoma are those of the P2Y types, such as P2Y1, P2Y2, and $\mathrm{P} 2 \mathrm{Y} 12$. P2Y1 receptors seem to reduce cell proliferation and P2Y2s usually appear to increase cell numbers [110], whereas P2Y12s have been related to tumor metastasis by platelet activation in melanoma cells [111].

Interestingly, one of the factors which leads to skin cancer, UV-B irradiation, seems to have a relationship with purinergic signaling. Severe effects have been associated with this irradiation type and shown to reduce the amount of $\mathrm{P} 2 \mathrm{X} 1$ and $\mathrm{P} 2 \mathrm{Y} 2$ receptors, as well as to destroy $\mathrm{P} 2 \mathrm{X} 7$ receptors, with the possibility of contributing to malignant transformation of keratinocytes [112].

Also regarding modulation receptors in the melanoma context, stimulation of A2AR and A3AR tumor cells may enhance proliferation triggering melanoma cells' death. Deletion of A2ARs in myeloid cells was shown to revert immunosuppression in B16-melanoma-bearing mice via potentiation of NK and cytotoxic $\mathrm{T}$ lymphocytes responses [113-115]. A study in vivo to understand the effect of A1R, A2AR, and A3R signaling in B16 melanoma in mice found that the receptors contribute to TME by modulating angiogenesis, neovascularization, and infiltration of immunosuppressive tumor-associated macrophages (TAMs) [116].

In addition to the receptors, ectonucleotidases, given their importance in the purinergic chain, have been shown as involved in cancer. Thus, in the melanoma context, inhibition of CD39 can lead to extracellular ATP accumulation, reinforcing the close relationship between this neoplastic disease and the activity of enzymes that hydrolyze adenine nucleotides. In addition, high ATP levels in the post-surgery $\mathrm{CM}$ microenvironment are suggested to be the cause of deleterious changes [109].

CD73 also seems to be involved in melanoma, since the studies indicate that high CD73 expression is suggestively present in the disease $[117,118]$. In the primary melanoma type, mutational status did not show any association with CD73 expression in metastatic lesions; however, patients with advanced cases tended to have more CD73 expression in their metastases [119]. Through a mouse model of melanoma, a CD73 inhibitor improved $\mathrm{T}$ and $\mathrm{B}$ cell-mediated anti-tumor immunity and reduced tumor growth [120].

Curiously, in addition to already established knowledge about CD73 capacity in the hydrolysis of nucleotides, it is involved in the invasion of cancer cells; it is also known that the nonenzymatic action of CD73 is to promote cell migration on ECM through activation of focal adhesion kinase (FAK) in melanoma cells [121].

\section{Natural compounds: the promising rosmarinic acid}

In the last years, due to technological advances, natural compounds, derivatives of living organisms, have been the target of several research studies involving human health, especially when it comes to anticancer action. They can be found in the entire nature and distributed in a wide range of world regions. Many papers have shown that, in general, these compounds can not only promote anticancer action, but also do apoptosis and arrest cell cycles [122-124]. 
Therefore, the phenolic compounds, present in almost all foods, are identified for having at least one aromatic ring with one or more hydroxyl groups. They can be found in fruits, vegetables, legumes, cereals, beer, coffee, wine, and spices, and are divided into classes called flavonoids, phenolic acids, phenolic alcohol, stilbenes, and lignins, according to their characteristics [125].

Among the phenolic acids, RA can be mentioned, which is a caffeic acid and a 3,4-dihydroxyphenyllactic acid derivative, present in herbal plants, especially in those from the Boraginaceae and Lamiaceae families, such as rosemary (Rosmarinus officinalis L.), basil (Ocimum basilicum), oregano (Origanum vulgare), sage (Salvia officinalis), and Melissa officinalis, with high desired pharmacological capacity in cancer treatment, namely: its antioxidant, antiinflammatory, and antitumor effects. Therefore, many kinds of research looking for these effects, in various cell lines and cancer types, were developed, and the findings appear to be promising [126-128].

In addition, regarding RA potential and considering the urgent need to identify novel treatments for melanoma due to the expensive conservative therapies [24, 129], it is reinforced that there are articles which have been presenting promising outcomes in other cancer contexts [130,131], but which can also be indicated as a promising compound as an adjuvant therapy on the treatment for this skin neoplasia, in spite of few works existing.

Concerning the chemical characteristics, the International Union of Pure and Applied Chemistry (IUPAC) nomenclature for RA is (2R)-3-(3,4-dihydroxyphenyl)-2-[(E)3-(3,4-dihydroxyphenyl)prop-2-enoyl]oxypropanoic acid, to present it as crystalline solid red-orange, with molecular formula $\mathrm{C}_{18} \mathrm{H}_{16} \mathrm{O}_{8}$, molecular weight of $360.3 \mathrm{~g} / \mathrm{mol}$, melting point of $171-175{ }^{\circ} \mathrm{C}$, well-soluble in most organic solvents, such as ethanol, dimethyl sulfoxide (DMSO), or dimethyl formamide (DMF), but little soluble in water. In its chemical structure (Fig. 2), there are two phenolic rings and two $\mathrm{OH}$ ortho-position groups in each ring, which promote its antioxidant activity through $\mathrm{H}$ grant, in addition to an unsaturated double bond, a carbonyl group, and a carboxylic acid group [132-134].

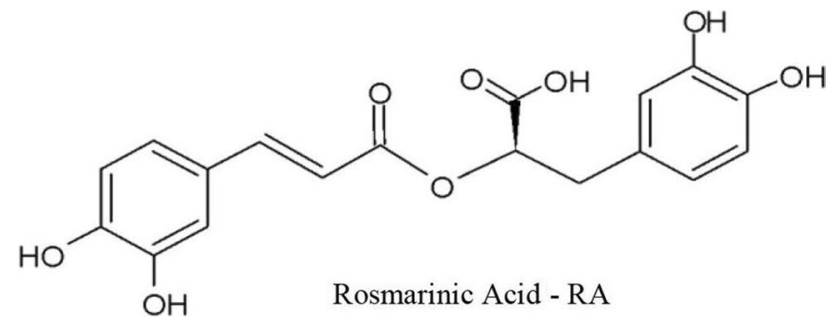

Fig. 2 Structural formula of RA. Chemical structure of phenolic compound rosmarinic acid $\left(\mathrm{C}_{18} \mathrm{H}_{16} \mathrm{O}_{8}\right)$
The vegetable genesis of RA depends, in summary, on two pathways: the caffeoyl part is formed by L-phenylalanine action through cinnamic and 4-coumaric acid, and, at the same time, 3,4-dihydroxyphenyllactic acid is modulated by the action of L-tyrosine in 4-hydroxyphenylpyruvic acid $[135,136]$. Each phase can be detailed as seen in Fig. 3, as well as the many enzymes involved in this mechanism.

Several studies were conducted to understand the pharmacokinetics to apply this compound on human beings and the indication that can be administered topically, pulmonary, intranasally, and via intravenous infusion, with the perioral route being the main form for intakes. Regarding metabolization, there is the tendency for it to occur by the intestinal microflora, where it is degraded to simple phenolic compounds by microorganisms, whereas distribution occurs by plasma albumins and excreted mainly through the renal system. Moreover, evidence has shown that herbal remedies containing RA reported no serious side effects and presented positive outcomes [137].

Despite the action mechanism of this compound not being in fact elucidated, many in vitro and in vivo studies were carried out to prove its anti-inflammatory effect [138], for example, describing the therapeutic potential of RA in inflammatory diseases such as colitis by reducing inflammatory cell infiltration, in addition to inhibiting induction of cyclooxygenase-2 (COX-2) and synthesis of IL-1 $\beta$, IL-6, and IL-22. Furthermore, a bibliographic review conducted by Yahfoufi et al. [139] proved the immunomodulatory role of in vivo and in vitro polyphenols, due to interference with immune cell regulation in miscellaneous pathways by inactivating NF- $\kappa \mathrm{B}$, modulating arachidonic acid pathways responsible for COX-2 synthesis, and inhibiting some enzymes involved in the production of ROS.

Jang et al. [140] also proved such efficacy to see cell arrest cycle and apoptosis through modulation of gene expression related to prostate cancer initiation, histone deacetylases (HDAC). In the same manner, in the study by Luo et al. [138], the effect of RA on oral cancer was analyzed and it was verified that there was inhibition of cell proliferation due to the selective apoptosis mode, since the inhibitory effect was less present in normal cells. It is also important to mention that RA also has the capacity to prevent metastasis of the colorectal cancer phosphorylation adenosine monophosphate-activated protein kinase (AMPK) pathway, an enzyme that preserves cell homeostasis [141].

In conformity, RA proved to be efficient as an antioxidant by reducing the free radicals resulting from renal ischemia/reperfusion lesions, the focus of the study by Ozturk et al. [142]. In doing so, this phenolic acid acts increasing the expression of cytoprotective genes, reducing the cytotoxicity induced by xanthine oxidase and hydrogen peroxide $\left(\mathrm{H}_{2} \mathrm{O}_{2}\right)$ and increasing the production 
Fig. 3 Possible hypothesis of RA biosynthesis. Initially, RA biosynthesis occurs in double parallel vias which unite to effectively form the phenolic acid molecule. One of the vias begins with precursor amino acid L-phenylalanine transformation by phenylalanine ammonialyase (PAT) to T-cinammic acid. Afterwards, T-cinnamic acid is converted to 4-coumaric acid by cinnamic acid 4-hydroxylase $(\mathrm{C} 4 \mathrm{H})$ with addition of one $\mathrm{OH}$-group in position 4 of the aromatic ring and subsequently transformed to 4-coumaryl-CoA by 4-coumarate-CoA ligase (4CL). Another via from amino acid L-tyrosine transformation, involving the tyrosine aminotransferase (TAT) enzyme, to 4-hydroxyphenylpyruvic acid and then, converted to 4-hydroxyphenyllactic acid by hydroxyphenylpyruvate reductase (HPPR). In the pre-final step, both vias are united; that is, the 4-coumaryl-CoA arising from the L-phenylalanine via and 4-hydroxyphenyllactic acid, from L-tyrosine, are incorporated by hydroxycinnamoylCoA hydroxyphenyllactate hydroxycinnamoyl transferase (RAS), and coenzyme A (CoA), present in 4-coumaryl-CoA, is released. Finally, RA via 3 - and $3^{\prime}$-hydroxylase (3-H, 3'-H) is synthetized with introduction of OH-groups in positions $3^{\prime}$ and 3 of the aromatic rings

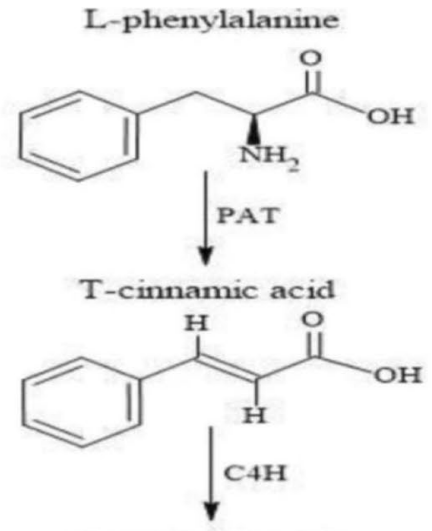

L-tyrosine<smiles>N[C@@H](Cc1ccc(O)cc1)C(=O)O</smiles>

4-hydroxyphenylpyruvic acid

4-coumaric acid<smiles>O=C(O)C=Cc1ccc(O)cc1</smiles>

4-coumaryl-CoA

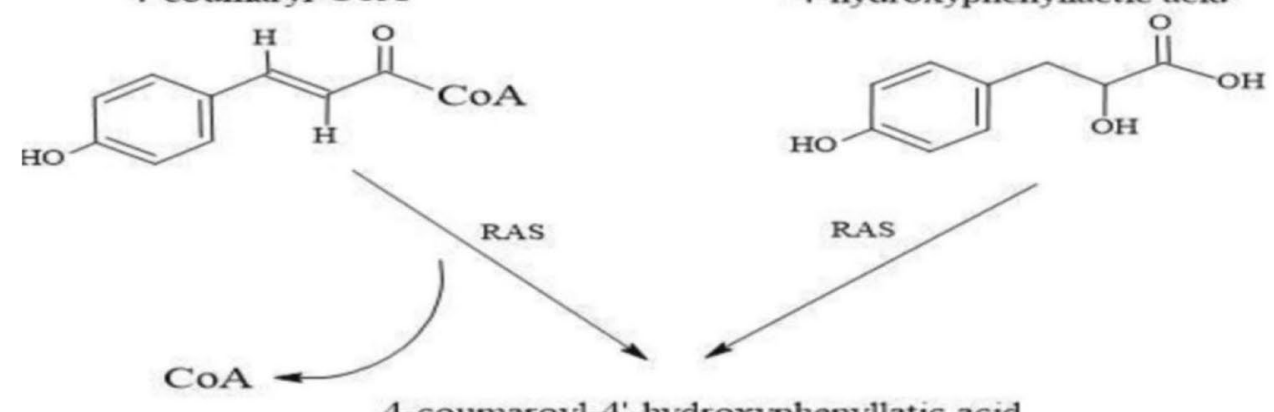

4-coumaroyl-4'-hydroxyphenyllatic acid

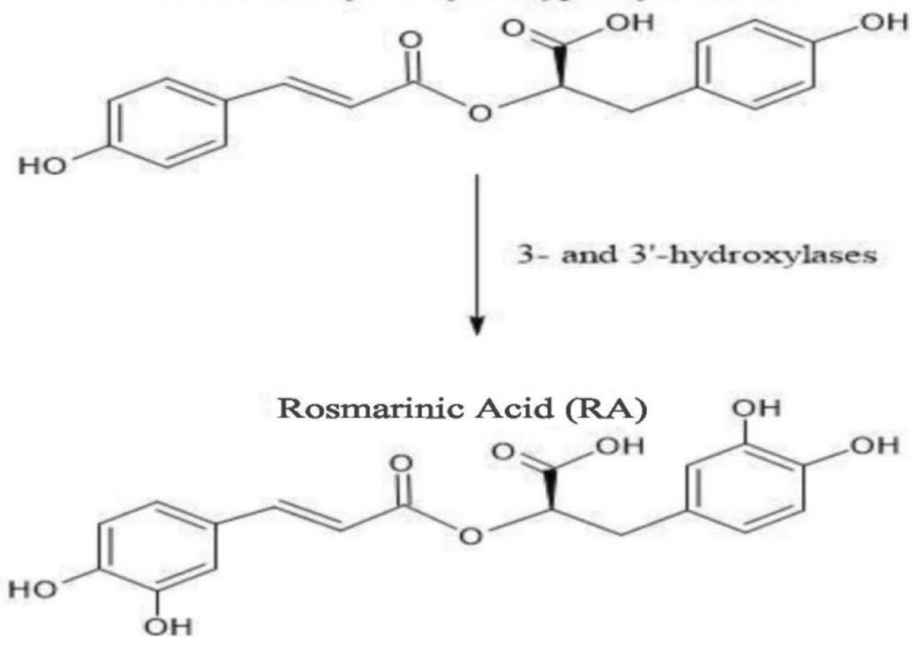

of prostaglandin E2 and reducing that of leukotriene B4, interleukin-6, interleukin-1-beta, and tumor necrosis factoralpha, in addition to inhibiting the activation of the complementary system. Jointly, phenolic acid has the ability to reduce the free radicals through the hydroxyl group, and RA showed more efficiency, with $98.92 \%$ of the total antioxidant activity [143].

\section{Anticancer and antitumor action of rosmarinic acid}

Concerning the scientific research studies relating cancer and the potential of RA in the human body, scarcity of data is observed, although studies conducted using in vitro assays and in vivo animal models are easily found in the literature. 
Table 3 presents some studies in different human cancer contexts where RA was used in vitro and in vivo, with their respective outcomes.

Countless research has evidenced RA in the treatment of cancer pathologies, but these action hypotheses are varied. One of them is the anti-inflammatory action, whereas the inflammatory process is closely related to tumor genesis, as previously mentioned. This action is proven by in vivo models, carried out by Swarup et al. [144] when reducing the mortality and pro-inflammatory cytokine levels in mice infected with the Japanese encephalitis virus. These researchers found a reduction in the IL-12, TNF- $\alpha$, IFN- $\gamma$, MCP-1, and IL-6 levels when compared to those infected without treatment. Similarly, the anti-inflammatory effects in a neuroinflammatory lesion were proved not only in an in vitro model but also in an in vivo one, when reducing the expression of Toll-like receptor 4 (TLR4) and CD14, transmembrane receptors that activate the NF-k $\beta$ pathway, in addition to suppressing the activation of NLRP3 inflammasome, responsible for the maturation of pro-inflammatory cytokines IL-1 $\beta$ and IL-18 [145].

Completing the previous idea, some papers indicate the potential of RA for immune effect, such as the one published by Lembo et al. [146], which shows the increase of immune parameters like phagocytic activity, as well as concentrations of some biochemical blood characteristics, such as total cholesterol and its fractions of lipoprotein, and triglycerides in treating an animal chicken model with a concentration of 100 or $200 \mathrm{mg}$ oil kg $\mathrm{kg}^{-1}$. To reinforce this data, this phenolic compound also presented an anti-inflammatory effect against local and systemic inflammation in rats [147], decreased TNF- $\alpha$, interferon- $\gamma$, IL-6, and IL-12 [148] levels, and significantly reduced MPO activity and TNF- $\alpha$ levels in mice [149].

As suggested by all these articles cited in Table 3, the apoptosis related to cell cycle arrest or alteration of apoptosis genes has strongly influenced the antitumor effect of RA. Both in the studies by Messeha et al. [17] and by Jang et al. [140], the use of this compound in breast and prostate cancer, respectively, revealed the apoptotic effect. At first, two breast cancer cell lines were analyzed, whose cell arrest occurred in the G0/G1 phase in one and in the S-phase in the other. In addition, the apoptotic gene expression, among the TNF, increased approximately 8.5 -fold. In the second article, RA also proved its potential in prostate cancer when inhibiting HDAC, an enzyme highly expressed in cell cancer and that negatively regulates the expression of $\mathrm{p} 53$, a tumor suppressor gene.

In the same way, the antiproliferative effect is also associated with the anticancer properties of RA. Videlicet was tested in cells of Panc-1 and SW1990 cell lines, in pancreatic cancer, since it reduced the number of colonies when compared to the control group, by increasing the expression of MiR-506, a tumor suppressor miRNA. In addition, in that study, not only was the antiproliferative capacity clear but also the reduction in the cell invasion and migration capacity that promotes apoptosis and suppresses epithelial-mesenchymal transition (EMT) in the pancreatic cancer cells [150].

Conversely, in hepatocellular carcinoma, the RA pathway involves inflammation and angiogenesis, according to Cao et al. [151]. By enzyme-linked immunosorbent assays (ELISAs), the levels of inflammatory factors TNF- $\alpha$, IL-6, and $\mathrm{IL}-1 \beta$, as well as of angiogenic factors (vascular endothelial growth factor, VEGF, and transforming growth factor- $\beta$, TGF-beta), were reduced when that phenolic compound was administered in mice. Furthermore, by Western blot, it was found that there was a reduction in the expression of $\mathrm{NF}-\mathrm{k} \beta \mathrm{p} 65$, which regulates the angiogenic factors during $\mathrm{CHC}$ development, and consequently resulting in an antiangiogenic effect. Also in that study, the results showed that the toxicological effects of RA were insignificant, in addition to obtaining a $100 \%$ survival rate in the mice.

Regarding the present time, the production of ROS can trigger the formation of new tumors and, for this reason, the antioxidant effect is a positive factor for antitumor action. The phenolic acids, through the hydroxyl group, are known for their antioxidant potential, which prevents their reaction with the DNA molecule, resulting in a mutation. Among the phenolic acids, RA was the most effective in this regard (98.92\% of activity) in addition to having the greatest chelating effect, followed by caffeic acid, and a protective effect in DNA against toxic substances like UV and $\mathrm{H}_{2} \mathrm{O}_{2}$ [143]. At last, according to Oguz et al. [152], it is an effective hepatoprotective agent and increases antioxidant capacity by reducing oxidative stress.

Moreover, the administration of RA in radio-resistant B16F10 lineage melanoma cells had a reducing effect on glutathione (GSH) after exposure to radioactivity irradiation, when compared to PNT2 prostate epithelial cells, considered radiosensitive. This effect is possibly due to the association with eumelanin synthesis pathways, intracellular consumption of GSH, and reduction of protective mechanisms against oxidative stress, which indicate a significant potential damage to radio-resistant cells during radiotherapy. It was observed that, at the same time, RA could present a protective action on healthy cells during therapy [153].

When analyzing RA as a promising compound for $\mathrm{CM}$ treatment, it is important that it prevents metastasis and, for this reason, that action was also to be searched and found in the literature. In a research study published in 2010 by Xu et al. [154], the antimetastatic action of this compound was already being studied, and, through experiments in animals, it has been proved that there is inhibition of metastasis in colorectal cancer (CRC) via the extracellular signal-regulated kinase pathway. More recently, Han et al. [141] report that such compound inhibits the proliferation of CRC cells, as well as hinders metastasis by AMPK phosphorylation. 
Table 3 Some studies with pure RA in different human cancer pathological contexts over the past three years. $\mathrm{IC}_{50}$ (half maximum inhibitory concentration), MARK4 (microtubule affinity regulating kinase 4), TNFRSF25 (TNF receptor superfamily 25), TNFSF10 (TNF superfamily member 10), TNFRSF11B (TNF receptor superfamily 11B), BNIP3 (BCL-2 interacting protein 3), BIRC5 (baculoviral IAP repeat-containing 5), GADD45A (growth arrest and DNA damage-inducible 45 alpha), $\mathrm{H}_{2} \mathrm{O}_{2}$ (hydrogen peroxide), EGFR (epidermal growth factor receptor),
NOX (NAD(P)H oxidase), PI3K/AKT/mTOR (phosphatidylinositol 3-kinase/serine-threonine protein kinase/mammalian target of rapamycin), MG132 (carbobenzoxy-L-z-L-leucyl-L-leucinal), AMPK (AMPactivated protein kinase), Bax (Bcl-2-associated X protein), HDAC2 (histone deacetylases 2), PARP-1 (poly(ADP-ribose)polymerase 1), and MALAT-1 (metastasis-associated lung adenocarcinoma transcript 1)

\begin{tabular}{|c|c|c|c|c|}
\hline Study type & Pathological context & Dose/time & Main findings & References \\
\hline $\begin{array}{l}\text { In vitro } \\
\text { A549 and MDA-MB-231 cells }\end{array}$ & $\begin{array}{l}\text { Basal alveolar adenocarci- } \\
\text { noma and breast cancer }\end{array}$ & $\begin{array}{l}\mathrm{IC}_{50} \text { and } 2 \times \mathrm{IC}_{50} \\
(72 \mathrm{~h}) \\
\mathrm{IC}_{50}=6.204 \mu \mathrm{M}\end{array}$ & $\begin{array}{l}\uparrow \text { apoptosis } \\
\downarrow \text { MARK4 protein } \\
\downarrow \text { cell proliferation }\end{array}$ & {$[15]$} \\
\hline $\begin{array}{l}\text { In vitro } \\
\text { Hep-G2 cells }\end{array}$ & Liver carcinoma & $\begin{array}{l}0,2.5,5,10,20,40,80,160 \text {, and } \\
320 \mu \mathrm{M} \text { to cell viability assay } \\
(12 \mathrm{~h}) \\
0,7,14,28 \mu \mathrm{M} \text { to apoptosis } \\
\quad \text { assay } \\
(24 \mathrm{~h}) \\
\mathrm{IC}_{50}=14 \mu \mathrm{M}\end{array}$ & $\begin{array}{l}\uparrow \text { apoptosis (caspase- } 3 \text { and } \\
\text { caspase-9) } \\
\downarrow \text { cell proliferation } \\
\text { - cytotoxic effect against liver } \\
\text { carcinoma cells }\end{array}$ & [16] \\
\hline $\begin{array}{l}\text { In vitro } \\
\text { TNBC cell lines: MDA-MB-231 } \\
\text { and MDAMB-468 }\end{array}$ & Triple-negative breast cancer & $\begin{array}{l}0-500 \mu \mathrm{M}(48-96 \mathrm{~h}) \\
\mathrm{IC}_{50}=350 \mu \mathrm{M}\end{array}$ & $\begin{array}{l}\uparrow \text { apoptosis (TNFRSF25, } \\
\text { TNFSF10, TNFRSF11B, } \\
\text { BNIP3, BIRC5 and } \\
\text { GADD45A) } \\
\downarrow \text { cell proliferation } \\
\text { - cycle arrest MDAMB-468 (S } \\
\text { phase) and MDA-MB-231 } \\
\text { (G0/G1 phase) }\end{array}$ & {$[17]$} \\
\hline $\begin{array}{l}\text { In vitro } \\
\text { HNSCC cell lines: UM-SCC-1, } \\
\text { UM-SCC- } 6 \text { and OSC2 }\end{array}$ & Head and neck carcinoma & $\begin{array}{l}80 \mu \mathrm{g} / \mathrm{mL} \text { single and combined } \\
\text { with blue light }(24-96 \mathrm{~h})\end{array}$ & $\begin{array}{l}\uparrow \text { apoptosis } \\
\downarrow \text { cell proliferation } \\
\downarrow \mathrm{H} 2 \mathrm{O} 2 \text { (EGFR increases NOX } \\
\quad \text { signaling) }\end{array}$ & {$[175]$} \\
\hline $\begin{array}{l}\text { In vitro } \\
\text { SMMC } 7721 \text { cells }\end{array}$ & Liver carcinoma & $\begin{array}{l}0,5,10,20,50,100,200,300 \\
400, \text { and } 500 \mu \mathrm{g} / \mathrm{mL}(24 \mathrm{~h}, \\
48 \mathrm{~h} \text {, and } 72 \mathrm{~h})\end{array}$ & $\begin{array}{l}\uparrow \text { apoptosis (PI3K/AKT/mTOR) } \\
\downarrow \text { cell proliferation }\end{array}$ & {$[14]$} \\
\hline $\begin{array}{l}\text { In vitro } \\
\text { Hep-G2 cells }\end{array}$ & Liver carcinoma & $0,10,100$, and $1.000 \mu \mathrm{M}(24 \mathrm{~h})$ & $\begin{array}{l}\uparrow \text { apoptosis } \\
\text { - increased MG132-induced } \\
\text { cytotoxicity, proteasome } \\
\text { inhibition, autophagy, cellular } \\
\text { stresses ( } 1000 \mu \mathrm{M} \text { only) }\end{array}$ & {$[176]$} \\
\hline $\begin{array}{l}\text { In vitro } \\
\text { HCT } 116 \text { cells }\end{array}$ & Colorectal cancer & $\begin{array}{l}0,50,100, \text { and } 200 \mu \mathrm{M} \\
(24 \mathrm{~h}, 48 \mathrm{~h}, 72 \mathrm{~h}, \text { and } 96 \mathrm{~h})\end{array}$ & $\begin{array}{l}\uparrow \text { apoptosis } \\
\downarrow \text { cell proliferation } \\
\downarrow \text { metastatic (AMPK phospho- } \\
\quad \text { rylation) }\end{array}$ & {$[141]$} \\
\hline $\begin{array}{l}\text { In vitro } \\
\text { PC- } 3 \text { and DU145 cells }\end{array}$ & Prostate cancer & $\begin{array}{l}25,50,100,200,250, \text { and } \\
300 \mu \mathrm{M} \\
(48 \mathrm{~h}-2 \text { weeks })\end{array}$ & $\begin{array}{l}\uparrow \text { apoptosis } \\
\downarrow \text { cell proliferation } \\
\downarrow \text { colony formation } \\
\downarrow \text { HDAC2 (enzyme involved in } \\
\text { tumor formation) } \\
\text { - modulated Bax, caspase- } 3 \text { and } \\
\text { PARP- } 1\end{array}$ & {$[140]$} \\
\hline $\begin{array}{l}\text { In vitro } \\
\text { OVCAR-3 cells }\end{array}$ & Ovarian cancer & $\begin{array}{l}0,5,10,20,40,80, \text { and } 160 \mu \mathrm{M} \\
(48 \mathrm{~h} \text { and } 72 \mathrm{~h}) \\
\mathrm{IC}_{50}=34.6 \text { and } 25.1 \mu \mathrm{M} / \mathrm{time} \\
\text { respectively }\end{array}$ & $\begin{array}{l}\uparrow \text { apoptosis } \\
\text { (MALAT-1) } \\
\downarrow \text { cell proliferation } \\
\text { - morphological alterations cells } \\
\quad \text { (shrinkage and rounding) }\end{array}$ & {$[12]$} \\
\hline $\begin{array}{l}\text { In vivo } \\
\text { nude mice }\end{array}$ & Liver carcinoma & $\begin{array}{l}0,5,10 \text {, and } 20 \mathrm{mg} / \mathrm{kg} \text { (for } \\
5 \text { days) }\end{array}$ & $\begin{array}{l}\downarrow \text { colony formation } \\
\downarrow \text { decreased volume and weight } \\
\text { of tumor (inhibited growth of } \\
\text { xenografts) }\end{array}$ & {$[14]$} \\
\hline $\begin{array}{l}\text { In vivo } \\
\text { BALB/c female mice }\end{array}$ & Colorectal cancer & $100 \mathrm{mg} / \mathrm{kg} /$ day (14 days) & $\begin{array}{l}\downarrow \text { metastatic (AMPK phospho- } \\
\quad \text { rylation) } \\
\downarrow \text { procaspase-9 and Bax } \\
\text { - cycle arrest of the G0/G1 phase }\end{array}$ & [141] \\
\hline
\end{tabular}


In advanced $\mathrm{CRC}$, the main invaded organs are the liver and the lungs, and the use of RA in this study drastically reduces the number of metastatic tumor nodules in the latter organs. That is because, for metastasis to occur, the cells must invade the extracellular matrix and then migrate to another site. During this process, however, cell invasion, migration, and adhesion occur, whose processes are induced by matrix metalloproteinases (MMP-2 and MMP-9). The action of RA consists of AMPK activation, which reduces the expression and activity of these proenzymes and, consequently, makes it difficult for the cancer cells to spread and promote metastasis [141].

Finally, regarding platelet aggregation, there are studies that searched for the influence of RA on this process, such as Zou et al. [155], who, through Danshen extract and having RA as active molecule, showed a potent inhibitory effect on the rats' platelets, aggregation induced by arachidonic acid, and that molecular docking thiol oxidoreductase enzyme (ERp57) is important for that process. Similarly, Salvia yunnanensis extract, which contains RA in its composition, inhibited ADP-induced rabbit platelet aggregation by binding rosmarinic acid with P2Y12R, cryptotanshinone, RA being fundamental in this outcome, which could be applied with antithrombotics [18].

With that, it is possible to notice that there are few works in the literature evidencing the potential of RA in CM treatment, considering the several outcomes presented previously and, when it comes to clinical trials, that number is even smaller, as well as those concerning the purinergic system. Thus, these verifications reinforce the need to better research and understand the mechanisms in that theme.

\section{The purinergic system can be the target of rosmarinic acid in a pharmacological therapeutic perspective for cutaneous melanoma}

In normal cells, hemostasis control occurs tightly through the production and release of growth factors, which regulate cell growth and proliferation and preserve normal tissue architecture. When these mechanisms are deregulated, homeostasis is also disrupted, leading to decreased apoptotic capacities, hyperproduction of growth factors, and, consequently, exacerbated and uncontrolled cell proliferation, as well as alterations in receptor molecules, which results in changes in the signaling cell pathway, and TME can increase [39].

In this aspect, the role of cell signaling seems to be involved in various mechanisms that can lead to cancer development, such as the microtubule affinity regulating kinase (MARK4) pathway that is associated with cancer progression and metastasis [156] and many other signaling pathways, such as NF-кB [157] and mTOR [14]. As shown before in another section of this paper, several studies have indicated the pharmaceutical potential of RA in modulating cell pathways in different cancer contexts; therefore, it can be a promising compound to be used in targeted therapies for molecules and receptors that participate in these processes.

Currently, interest in researching purinergic signaling, which is a cell pathway multistep coordinated cascade where ATP, ADP, and Ado act, has been growing because of evidence that confirms its important role in inflammatory processes, immune response, and cancer progression in different cell types $[11,102,158]$. These nucleotides and corresponding nucleoside involved in purinergic signaling have specific effects, depending on cell type and agonist/ antagonist receptor-ligand [87].

The dynamics of the biochemical and cellular composition of TME are very important for the regulation of tumor cell metabolism, proliferation, motility, and dissemination, and can promote a protective effect or facilitate tumor progression [159, 160]. In this sense, ATP and Ado have recently been detected in high concentrations in TME [11, 92], ATP being frequently associated with the pro-inflammatory response, which plays a significant role in promoting antitumor effects, whereas Ado, a product of the hydrolysis of these nucleotides, presents immunosuppressive effects as negative-feedback, which prevents inflammation and tissue damage [161].

Another factor present in TME and that can be connected with purinergic signaling is lactate, arising from a phenomenon known as the Warburg effect, which occurs in most cancer cells. This phenomenon happens before the blood vessels are formed, where they nourish through the change in metabolic pathways and acquire energy via the glycolytic cascade under aerobics conditions [162]. Data indicates that cancer cells synthesize ATP via the Warburg effect, which leads to lactate formation and TME acidification [163], and, even in lower glucose concentrations, these cells can grow, differently from normal cells [39].

Thus, a plausible mechanism to this is that cancer cells expressing P2X7 receptors and activated by ATP, via the PI3K-AKT pathway, cause a moderate increase in the concentration of mitochondrial $\mathrm{Ca}^{2+}$, stimulation of oxidative phosphorylation (OXPHOS), and increased ATP generation. Activation of this receptor upregulates the expression of the glucose transporter 1 (GLUT1) plasma membrane glucose transporter and the expression of several enzymes of the glycolytic cascade. This leads to increased lactate generation, which is extruded from cancer cells by monocarboxylate transporter 4 (MCT4), causing acidification of the tumor microenvironment, but is also taken up via monocarboxylate transporter 1 (MCT1) and used as a metabolite for energygenerating reactions in tumor cells. Lactate has been associated with inhibition of maturation (DCs) and with promoters 
of macrophage differentiation, which can contribute to cancer cell proliferation, migration, and invasion [11].

Curiously, although other receptors with anticancer potential are described in the literature, P2X7, expressed by cancer cells as in CM, is the most associated with tumor cell killing via ATP $[82,164,165]$. On the other hand, P2X7 is overexpressed in some tumors and leukemias, which is associated with cancer progression and low survival prognosis [166], which could be explained from the hypotheses described above. It is to be highlighted that no specific agonist to this receptor has been described up to the present day [167].

In this context, the reduction of the Warburg effect seems to be an interesting strategy for CM treatment in the initial stage, because lactate can prevent tumor death in the microenvironment, as already shown, but there is little evidence about the modulation capacity of compounds that promote this mechanism. A study published in 2015 showed that RA has the ability to inhibit lactate generation through the suppression of HIF- $1 \alpha$; in this way, it presented a strong capacity to inhibit the Warburg effect in gastric cancer [168]. Regarding this theme, later papers have not been easily found in literature, and, considering these promising results, this phenolic acid could be a novel agent possibility arising to treat melanoma.

Nevertheless, following the reverse of what was proposed by Di Virgilio et al. [11], with the use of RA in CM treatment, this molecule could be a blocker of the P2X7R target and an inhibitor of the PI3K-AKT pathway, thereby suppressing HIF- $1 \alpha$, increase of $\mathrm{Ca}^{2+}$, and, consequently, reduction of ATP in OXPHOS generation, as well as ATP release for this receptor. Furthermore, without PI3K-AKT activation, the GLUT1 transporter does not have the capacity to promote glucose intake, and lactate generation would be harmed. Finally, with less lactate release, the $\mathrm{pH}$ of TME can be altered and other mechanisms involved with tumor killing can be restored, such as immune responses (Fig. 4).

From another perspective, ATP signaling acts as immunosuppression in CM, as it is degraded to ADP and AMP in TME, promoting proliferation of regulatory $\mathrm{T}$ cells [97]. ADP is the main platelet recruiter, acting in the P2Y1 and P2Y12 G-protein-coupled receptors. While the first initiates platelet activation by morphological changes and has a weak response to ADP, the second has an effective response when promoting recruitment of these thrombocytes. For this reason, the use of P2Y12 inhibitors has been a therapeutic target for many pathologies, cancer among them [169].

The P2Y12 receptor is an important tumor growth modulator, since it promotes platelet activation by cancer cells. Once activated, it releases TGF- $\beta$ and increases tumor cell adhesion to the endothelium, metastasis, angiogenesis, and drug resistance. This fact is verified by in vitro models which predict its in vivo aggressiveness when this event occurs. Consequently, by preventing the action of this receptor, the tumor would stop growing and this was observed in some types of cancer, such as ovarian and colorectal [170, 171].

With this purpose, data from the literature prove that $\mathrm{Sal}$ via yunnanensis (SY) is an herb rich in several compounds, including RA, which acts by blocking platelet aggregation induced by ADP and arachidonic acid through the P2Y12 receptor. Although the $\mathrm{P} 2 \mathrm{Y} 1$ and $\mathrm{P} 2 \mathrm{Y} 12$ receptors act in the formation of platelets, only $\mathrm{P} 2 \mathrm{Y} 12$ is related to thrombin and other platelet agonists and, therefore, is the target of another hypothesis of this study. They are located in platelets and in the central nervous system, especially in microglia [18].

Thus, when analyzing the effects of the SY components, RA proved to be one of the main antiplatelet constituents in two ways: the first is the inhibitory effect of ERp57, a thiol oxidoreductase enzyme from the family of protein disulfide isomerase (PDI), which has an influence on platelet aggregation induced by arachidonic acid [155]. In addition, using molecular docking at the $\mathrm{P} 2 \mathrm{Y} 12$ receptor, a high affinity between them and an ADP antagonistic effect was observed, which resulted in the inhibition of platelet aggregation [18].

Given the aforementioned, Mânica et al. [97] suggest that platelets are activated in patients with $\mathrm{CM}$ and that it can be a key to metastasis in this disease. This supports the use of RA as a potential tumor progression switch by purinergic signaling in $\mathrm{P} 2 \mathrm{Y} 12$, since the immunosuppression caused by the ATP levels and which acts on this process can be inhibited by modulating these nucleotide and nucleoside degradation enzymes. Consequently, it is known that most of the cellular mutations are controlled by the immune system, which first tries to correct them by specialized intracellular proteins and, when that does not occur, the cell undergoes apoptosis. However, immunosuppression does not allow this control and, therefore, is closely related to the development, progression, and recurrence of the tumor. Therefore, by suppressing immunosuppression, the action of the immune cells can be resumed [172].

Knowing this, another possibility to treat $\mathrm{CM}$ based on the modulation of purinergic signaling by RA could be targeting P2Y12, leveraging the opportunity that the antagonist capacity of this molecule has on this receptor. Thereby, grounded on Ballerini et al. [173] and on Mânica et al. [97], since the action of RA on the P2Y12 receptor exerts an antagonist effect, it prevents ADP-ligand and inhibits adenylate cyclase (AC) and subsequent cascades, such as cyclic adenosine monophosphate (cAMP) and protein kinase A (PKA), which finally inhibits phosphorylation of vasodilator-stimulated phosphoprotein (VASP), in turn harming the expression of adhesive proteins in the membrane surface of $\mathrm{CM}$ cells and adhesion between cells. This mechanism promotes decreased tumor mass and, in turn, constrains tumor progression and metastasis (Fig. 5). 


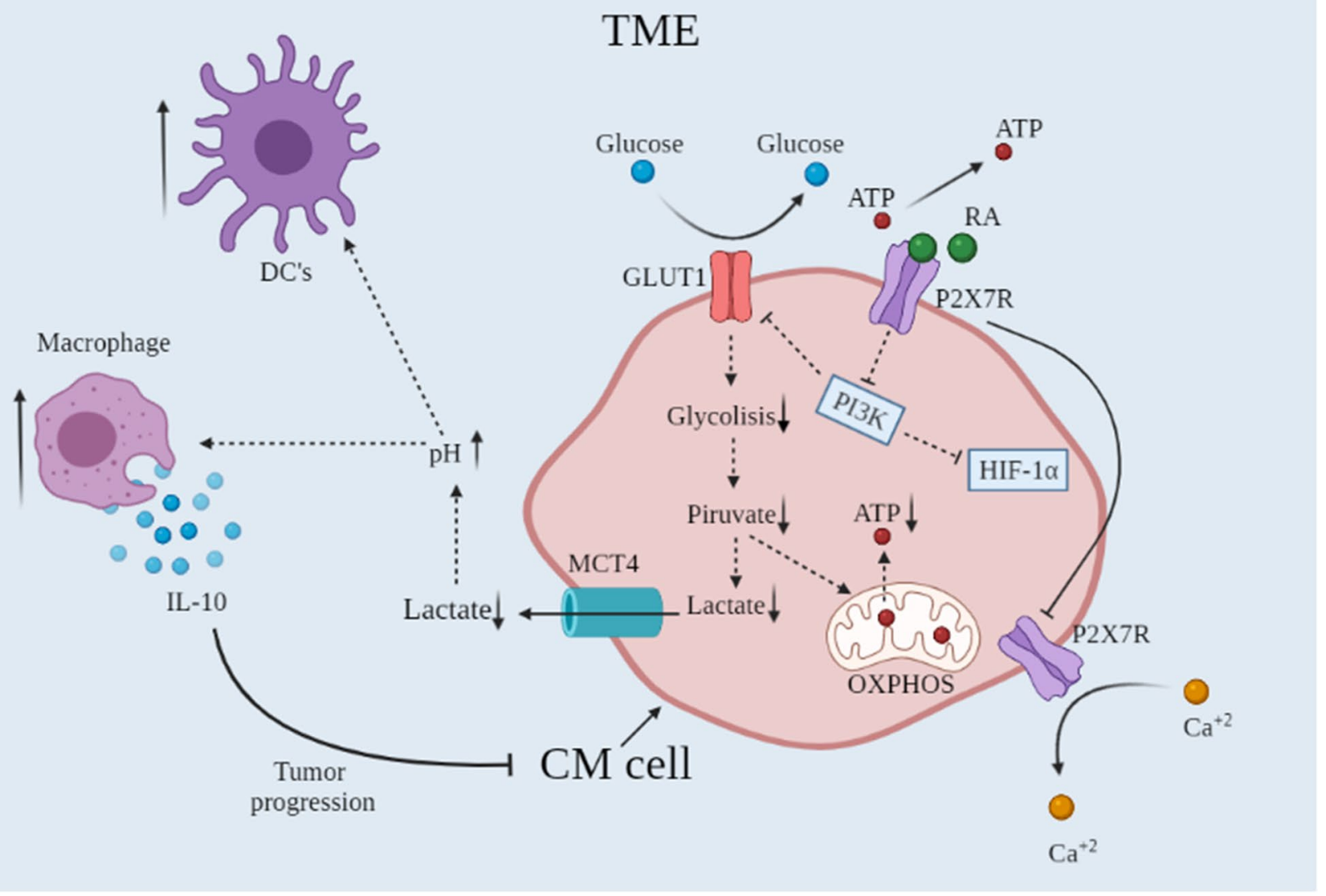

Fig. 4 Possible mechanism to block the P2X7 receptor and inhibit the Warburg effect through RA action. Since ionotropic purine receptor $\mathrm{P} 2 \mathrm{X}$ type 7 (P2X7) is prevented from ATP-ligand by RA blocking, uptake of calcium ion $\left(\mathrm{Ca}^{2+}\right)$ is decreased and oxidative phosphorylation (OXPHOS) in the mitochondria downregulates ATP generation and release. In addition, the blocked P2X7 inhibits the phosphoinositide-3-kinase (PI3K-AKT) pathway, which downregulates the expression of glucose transporter 1 (GLUT1) in the plasma mem-

\section{Final considerations}

This review work explored the potential antitumor effects of RA in different cancer contexts and brought up the hypothesis of its pharmacological application in the purinergic system as a treatment for CM. Nevertheless, for being an unprecedented work, the scarcity of articles evidencing the action of this compound in this signaling pathway requires further studies to be corroborated and proved. In addition, although there is consistent data on this anticancer potential in in vitro models, there are few articles portraying this experience in in vivo models and, in particular, in skin cancer.

Given this scenario, it is extremely important that the pharmacological potential of this phenolic acid as an option is further explored, especially when considering its brane with a reduction of glucose intake and mitigates $\mathrm{pH}$ acidification in TME due to lactate release by monocarboxylate transporter 4 (MCT4) from the aerobic glycolysis cascade. With $\mathrm{pH}$ regulated, there is chemiotaxis of the immune cells as DCs and macrophages, and a reduction in the secretion of cytokine IL-10 with inhibition of tumor progression. At the same time, with PI3K-AKT inhibition, there is no stimulus of hypoxia-inducible factor $1 \alpha$ (HIF-1 $\alpha)$ and, consequently, a reduction in mitogenic/angiogenic inductors

aggressiveness, lack of effective therapeutic options, and ease of finding this compound in different sources. In spite of this, the results explored so far are positive, which allows us to believe in a new path to be followed when it comes to $\mathrm{CM}$ treatment.

That said, the literature indicates that the purinergic system is involved in the physiopathology of cancer, such as in CM. Moreover, RA seems to have an anticancer effect in different cancer contexts and to act on purinergic signaling. Considering this evidence, we hypothesize that RA can be an effective candidate for the adjuvant treatment of $\mathrm{CM}$ acting as a modulating molecule of purinergic cell pathways. On the one hand, there is a possibility, through P2X7 blocking by RA, of mitigating the Warburg effect, which negatively interferes on the microenvironment due to releasing exacerbated lactate from the glycolysis pathway, which leads 


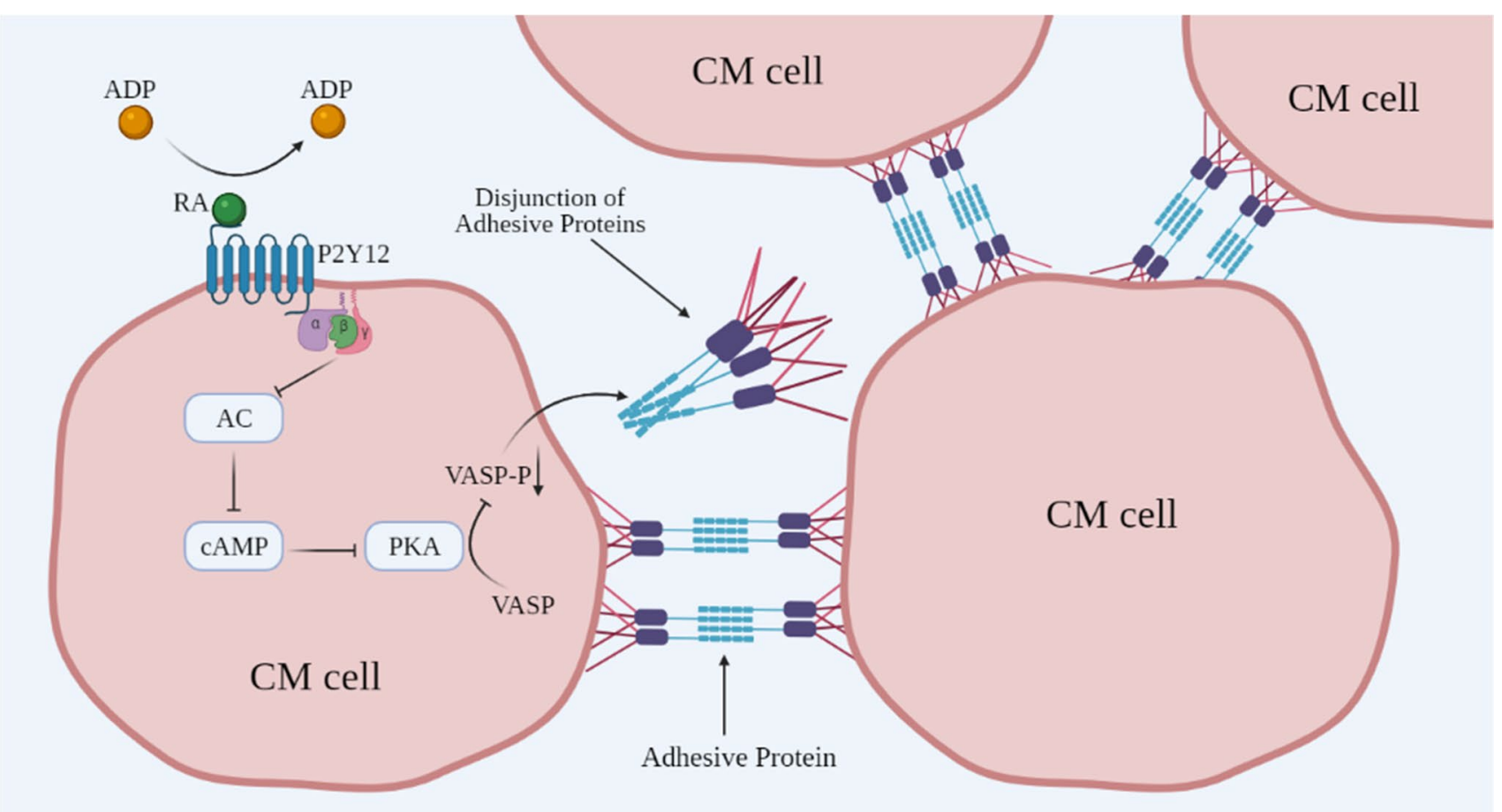

TME

Fig. 5 Hypothesis of RA antagonism in P2Y12 receptor acting against progression of tumoral events. The ADP-like antagonism effect of RA on metabotropic purine receptor P2Y type 12 (P2Y12) prevents ADP-ligand, thus avoiding the intracellular cascade linked to activation of adenylate cyclase (AC) and its second messenger,

to $\mathrm{pH}$ alteration and suppression of tumor-killing mechanisms, such as the immune response. On the other hand, an interesting alternative is to modulate the P2Y12 receptor by the RA antagonic molecule, reducing the formation of adhesive molecules to prevent adherence in tumor cells, and tumor mass inhibition, in turn constraining tumor progression and metastasis. In this way, our proposals for CM treatment based on targeting purinergic signaling permeate the integral practice, going from intracell to TME, which can be more effective than the techniques hitherto employed.

Undoubtedly, much is still to be discovered and elucidated about this promising compound, mainly concerning the pharmacological perspectives for $\mathrm{CM}$, this paper being an interesting work baseline to support more research and, perhaps, promote new evidence for the development of clinical trials in human beings, which is very important in the improvement of CM treatment.

Funding The authors would like to thank Universidade Federal da Fronteira Sul - UFFS for the partnership.

Data availability Not applicable. cyclic adenosine monophosphate (cAMP), which does not promote activation of protein kinase A (PKA) to vasodilator-stimulated phosphoprotein (VASP) phosphorylation. All that intracell signaling leads to downregulation of the adhesive proteins' expression in the plasma membrane, reducing tumor mass formation in TME

\section{Declarations}

Conflicts of interest Gilnei Bruno da Silva declares that she has no conflict of interest.

Milena Ayumi Yamauchi declares that she has no conflict of interest. Daniela Zanini declares that she has no conflict of interest.

Margarete Dulce Bagatini declares that she has no conflict of interest.

Ethical approval This article does not contain any studies with human participants or animals performed by any of the authors.

Informed consent All authors are in agreement with the content of the manuscript and with the submission.

\section{References}

1. IARC - International Agency of Research in Cancer (2020). CANCER TODA Available in: http://gco.iarc.fr/today/home. Accessed in: may. 2021.

2. Paddock LE et al (2016) Skin self-examination and long-term melanoma survival. Melanoma Res 26(4):401-408. https://doi. org/10.1097/CMR.0000000000000255

3. INCA - Instituto Nacional do Câncer (Brazil). Estimative 2020: cancer incidence in Brazil. [Brasília, DF]: Instituto Nacional do 
Câncer, 2018. Available in: https://www.inca.gov.br/publicacoes/ livros/estimativa-2020-incidencia-de-cancer-no-brasil. Accessed May 2021

4. INCA - Instituto Nacional do Câncer (Brazil). Cancer of skin melanoma. [Brasília, DF]: Instituto Nacional do Câncer, 2021. Available in: https://www.inca.gov.br/tipos-de-cancer/cancerde-pele-melanoma. Acessed May 2021

5. Carr S, Smith C, Wernberg J (2020) Epidemiology and risk factors of melanoma. Surg Clin North Am 100(1):1-12. https:// doi.org/10.1016/j.suc.2019.09.005

6. Siegel R, Naishadham D, Jemal A (2013) Cancer statistics, 2013. CA: A Cancer Journal for Clinicians, 63(1)11-30. https://doi.org/10.3322/caac.21166.

7. Wilson, M. A.; Schuchter, L. M. Chemotherapy for melanoma. In: KAUFMAN, H. L.; MEHNERT, J. M. (Eds.). Melanoma. Cancer Treatment and Research. Cham: Springer International Publishing, 2016;167:209-229. https://doi.org/10.1007/ 978-3-319-22539-5 8.

8. Schadendorf, D. et al. Melanoma. The Lancet, 392(10151)971984, sept. 2018. https://doi.org/10.1016/S0140-6736(18) 31559-9.

9. Gao Z, Dong K, Zhang H (2014) The roles of CD73 in cancer. Biomed Res Int 1-9:2014. https://doi.org/10.1155/2014/ 460654

10. Ferrari D, Malavasi F, Antonioli L (2017) A purinergic trail for metastases. Trends Pharmacol Sci 38(3):277-290. https://doi. org/10.1016/j.tips.2016.11.010

11. Di Virgilio F et al (2018) Extracellular ATP and P2 purinergic signalling in the tumour microenvironment. Nat Rev Cancer 18(10):601-618. https://doi.org/10.1038/s41568-018-0037-0

12. Zhang, Y. et al. Anticancer effects of rosmarinic acid in OVCAR-3 ovarian cancer cells are mediated via induction of apoptosis, suppression of cell migration and modulation of lncRNA MALAT-1 expression. Journal of B.U.ON.: official journal of the Balkan Union of Oncology, 23(3)763-768, 2018.

13. Pelinson LP et al (2019) Antiproliferative and apoptotic effects of caffeic acid on Sk-Mel-28 human melanoma cancer cells. Mol Biol Rep 46(2):2085-2092. https://doi.org/10.1007/ s11033-019-04658-1

14. Wang L et al (2019) Rosmarinic acid inhibits proliferation and invasion of hepatocellular carcinoma cells SMMC 7721 via PI3K/AKT/mTOR signal pathway. Biomed Pharmacother 120:109443. https://doi.org/10.1016/j.biopha.2019.109443

15. Anwar, S. et al (2020) Rosmarinic acid exhibits anticancer effects via MARK4 inhibition. Sci Rep 10(1)10300. https://doi.org/10. 1038/s41598-020-65648-Z

16. JIN, B. et al. Detailed studies on the anticancer action of rosmarinic acid in human Hep-G2 liver carcinoma cells: evaluating its effects on cellular apoptosis, caspase activation and suppression of cell migration and invasion. Journal of B.U.ON.: official journal of the Balkan Union of Oncology, 25(3)1383-1389, 2020.

17. Messeha SS et al (2020) Rosmarinic acid-induced apoptosis and cell cycle arrest in triple-negative breast cancer cells. Eur J Pharmacol 885:173419. https://doi.org/10.1016/j.ejphar.2020.173419

18. Li Y et al (2020) Screening for the antiplatelet aggregation quality markers of Salvia yunnanensis based on an integrated approach. J Pharm Biomed Anal 188:113383. https://doi.org/10. 1016/j.jpba.2020.113383

19. Nguyen AV, Soulika AM (2019) The dynamics of the skin's immune system. International Journal of Molecular Sciences, 20(8). https://doi.org/10.3390/ijms20081811

20. Enninga EAL et al (2017) Survival of cutaneous melanoma based on sex, age, and stage in the United States, 1992-2011. Cancer Med 6(10):2203-2212. https://doi.org/10.1002/cam4.1152
21. INCA - Instituto Nacional do Câncer (Brazil). Online mortality atlas. (Brasília, DF): Instituto Nacional do Câncer, 2019. Available in: https://mortalidade.inca.gov.br/MortalidadeWeb/pages/ Modelo08/consultar.xhtml\#panelResultado. Accessed May 2021

22. Rebecca, V. W.; Somasundaram, R.; Herlyn, M. Pre-clinical modeling of cutaneous melanoma. Nature Communications, 11(1)2858, 2020. https://doi.org/10.1038/s41467-020-15546-9.

23. Michielin O et al (2019) Cutaneous melanoma: ESMO Clinical Practice Guidelines for diagnosis, treatment and follow-up. Ann Oncol 30(12):1884-1901. https://doi.org/10.1093/annonc/ mdz411

24. Davis LE, Shalin SC, Tackett AJ (2019) Current state of melanoma diagnosis and treatment. Cancer Biol Ther 20(11):13661379. https://doi.org/10.1080/15384047.2019.1640032

25. Liu, V. et al. Pathologic characteristics of melanoma (2020). UpToDate. Available in: https://www.uptodate.com/contents/ pathologic-characteristics-of-melanoma?search=diagnos is $\% 20$ of $\% 20$ cutaneous $\% 20$ melanoma\&source $=$ search_result\&selected Title $=2 \sim 150 \&$ usage_ty pe $=$ default $\&$ display_rank $=2$. Accessed May 2021

26. Cabrera R, Recule F (2018) Unusual clinical presentations of malignant melanoma: a review of clinical and histologic features with special emphasis on dermatoscopic Findings. Am J Clin Dermatol 19(Suppl 1):15-23. https://doi.org/10.1007/ s40257-018-0373-6

27. Swetter, S; Geller, A. C. Melanoma: clinical features and diagnosis. UpToDate. 2020. Available in: https://www.uptodate.com/ contents/melanoma-clinical-features-and-diagnosis. Accessed May 2021

28. Elder DE et al (2020) The 2018 World Health Organization classification of cutaneous, mucosal, and uveal melanoma: detailed analysis of 9 distinct subtypes defined by their evolutionary pathway. Arch Pathol Lab Med 144(4):500-522. https://doi.org/10. 5858/arpa.2019-0561-RA

29. Volkovova, K. et al. Associations between environmental factors and incidence of cutaneous melanoma. Review. Environmental Health, 11(Suppl 1)S12, 2012. https://doi.org/10.1186/ 1476-069X-11-S1-S12.

30. Sample A, He YY (2018) Mechanisms and prevention of UVinduced melanoma. Photodermatol Photoimmunol Photomed 34(1):13-24. https://doi.org/10.1111/phpp.12329

31. Paulson KG et al (2020) Age-specific incidence of melanoma in the United States. JAMA Dermatol 156(1):57-64. https://doi.org/ 10.1001/jamadermatol.2019.3353

32. Rastrelli $\mathrm{M}$ et al (2014) Melanoma: epidemiology, risk factors, pathogenesis, diagnosis and classification. In Vivo (Athens, Greece) 28(6): 1005-1011

33. Barbosa KBF et al (2010) Estresse oxidativo: conceito, implicações e fatores modulatórios. Rev Nutr 23(4):629-643. https:// doi.org/10.1590/S1415-52732010000400013

34. Schmatz R (2011) Efeitos do resveratrol, do suco de uva e do vinho tinto nos biomarcadores de estresse oxidativo e na atividade de ectoenzimas em ratos diabéticos. 2011. Thesis (PhE in Byological Science: Toxicological Biochemistry) - Universidade Federal de Santa Maria, Santa Maria - RS

35. Kudryavtseva, A. V. et al. Mitochondrial dysfunction and oxidative stress in aging and cancer. Oncotarget, 7(29)44879-44905, 2016. https://doi.org/10.18632/oncotarget.9821.

36. Pizzino $\mathrm{G}$ et al (2017) Oxidative stress: harms and benefits for human health. Oxid Med Cell Longev 2017. https://doi.org/10. 1155/2017/8416763

37. CANNAVÒ, S. P. et al. The role of oxidative stress in the biology of melanoma: A systematic review. Pathology - Research and Practice 215(1)21-28, 2019. https://doi.org/10.1016/j.prp.2018. 11.020 . 
38. Hanahan D, Weinberg RA (2011) Hallmarks of cancer: the next generation. Cell 144(5):646-674. https://doi.org/10.1016/j.cell. 2011.02.013

39. Hanahan D, Weinberg RA (2000) The hallmarks of cancer. Cell 100(1):57-70. https://doi.org/10.1016/S0092-8674(00)81683-9

40. Liberti MV, Locasale JW (2016) The Warburg effect: how does it benefit cancer cells? Trends Biochem Sci 41(3):211-218. https:// doi.org/10.1016/j.tibs.2015.12.001

41. Hsu PP, Sabatini DM (2008) Cancer cell metabolism: Warburg and beyond. Cell 134(5):703-707. https://doi.org/10.1016/j.cell. 2008.08.021

42. Scott DA et al (2011) Comparative metabolic flux profiling of melanoma cell lines. J Biol Chem 286(49):42626-42634. https:// doi.org/10.1074/jbc.M111.282046

43. Icard, P.; Lincet, H. A global view of the biochemical pathways involved in the regulation of the metabolism of cancer cells. Biochimica et Biophysica Acta (BBA) - Reviews on Cancer, 1826(2)423-433, 2012. https://doi.org/10.1016/j.bbcan.2012. 07.001 .

44. Vander Heiden MG, Cantley LC, Thompson CB (2009) Understanding the Warburg Effect: the metabolic requirements of cell proliferation. Science 324(5930):1029-1033. https://doi.org/10. 1126/science. 1160809

45. Hall, A. et al. Dysfunctional oxidative phosphorylation makes malignant melanoma cells addicted to glycolysis driven by the V600EBRAF oncogene. Oncotarget, 4(4)584-599, 30 apr. 2013. https://doi.org/10.18632/oncotarget.965.

46. Lyssiotis CA, Kimmelman AC (2017) Metabolic interactions in the tumor microenvironment. Trends Cell Biol 27(11):863-875. https://doi.org/10.1016/j.tcb.2017.06.003

47. Jones W, Bianchi K (2015) Aerobic glycolysis: beyond proliferation. Front Immunol 6. https://doi.org/10.3389/fimmu.2015. 00227

48. Fischer GM et al (2018) Metabolic strategies of melanoma cells: mechanisms, interactions with the tumor microenvironment, and therapeutic implications. Pigment Cell Melanoma Res 31(1):1130. https://doi.org/10.1111/pcmr.12661

49. Hinshaw DC, Shevde LA (2019) The tumor microenvironment innately modulates cancer progression. Can Res 79(18):45574566. https://doi.org/10.1158/0008-5472.CAN-18-3962

50. Whitton B et al (2018) Vacuolar ATPase as a potential therapeutic target and mediator of treatment resistance in cancer. Cancer Med 7(8):3800-3811. https://doi.org/10.1002/cam4.1594

51. Chen J et al (2021) Warburg effect is a cancer immune evasion mechanism against macrophage immunosurveillance. Front Immunol 11:621757. https://doi.org/10.3389/fimmu.2020. 621757

52. Tan $\mathrm{Z}$ et al (2015) The Monocarboxylate transporter 4 is required for glycolytic reprogramming and inflammatory response in macrophages. J Biol Chem 290(1):46-55. https://doi.org/10.1074/jbc. M114.603589

53. Gottfried E et al (2006) Tumor-derived lactic acid modulates dendritic cell activation and antigen expression. Blood 107(5):20132021. https://doi.org/10.1182/blood-2005-05-1795

54. Frauwirth KA et al (2002) The CD28 Signaling pathway regulates glucose metabolism. Immunity 16(6):769-777. https://doi. org/10.1016/S1074-7613(02)00323-0

55. Payen VL et al (2020) Monocarboxylate transporters in cancer. Molecular. Metabolism 33:48-66. https://doi.org/10.1016/j.molmet.2019.07.006

56. Fischer K et al (2007) Inhibitory effect of tumor cell-derived lactic acid on human T cells. Blood 109(9):3812-3819. https:// doi.org/10.1182/blood-2006-07-035972

57. Harmon C et al (2019) Lactate-mediated acidification of tumor microenvironment Induces apoptosis of liver-resident NK cells in colorectal liver metastasis. Cancer Immunol Res 7(2):335-346. https://doi.org/10.1158/2326-6066.CIR-18-0481

58. Morrot A et al (2018) Metabolic symbiosis and immunomodulation: how tumor cell-derived lactate may disturb innate and adaptive immune responses. Front Oncol 8:81. https://doi.org/ 10.3389/fonc.2018.00081

59. Levine AJ, Puzio-Kuter AM (2010) The control of the metabolic switch in cancers by oncogenes and tumor suppressor genes. Science 330(6009):1340-1344. https://doi.org/10.1126/science. 1193494

60. Czarnecka, A. M. et al. Targeted therapy in melanoma and mechanisms of resistance. International Journal of Molecular Sciences, 21(13)4576, 2020. https://doi.org/10.3390/ijms211345 76.

61. Pasquali, S. et al. Systemic treatments for metastatic cutaneous melanoma. The Cochrane Database of Systematic Reviews, 2018(2)CD011123, 2018. https://doi.org/10.1002/14651858. CD011123.pub2.

62. Moreira, A. et al. Current melanoma treatments: where do we stand? Cancers, 13(2)221, 2021. https://doi.org/10.3390/cance rs13020221.

63. Namikawa, K.; Yamazaki, N. Targeted therapy and immunotherapy for melanoma in Japan. Current Treatment Options in Oncology, 20(1)7, 2019. 10.1007 / s11864-019-0607-8.

64. Ramos-Casals, M. et al. Immune-related adverse events of checkpoint inhibitors. Nature Reviews. Disease Primers, 6(1)38, 2020. https://doi.org/10.1038/s41572-020-0160-6.

65. Eddy, K.; Chen, S. Overcoming immune evasion in melanoma. International Journal of Molecular Sciences, 21(23)8984, 2020. https://doi.org/10.3390/ijms21238984.

66. Luke JJ et al (2017) Targeted agents and immunotherapies: optimizing outcomes in melanoma. Nat Rev Clin Oncol 14(8):463482. https://doi.org/10.1038/nrclinonc. 2017.43

67. Hartman, R. I.; LIN, J. Y. Cutaneous melanoma-a review in detection, staging, and management. Hematology/Oncology Clinics of North America, 33(1)25-38, 2019. https://doi.org/10. 1016/j.hoc.2018.09.005.

68. Curti BD, Faries MB (2021) Recent advances in the treatment of melanoma. N Engl J Med 384(23):2229-2240. https://doi.org/10. 1056/NEJMra2034861

69. Kasakovski, D. et al. Advances in targeting cutaneous melanoma. Cancers, 13(9)2090, 2021. 10.3390 / cancers13092090.

70. Baust JM et al (2017) Best practices in cell culture: an overview. In Vitro Cellular \& Developmental Biology - Animal 53(8):669 672. https://doi.org/10.1007/s11626-017-0177-7

71. Mirabelli P, Coppola L, Salvatore M (2019) Cancer cell lines are useful model systems for medical research. Cancers 11(8). https://doi.org/10.3390/cancers 11081098

72. Burnstock $\mathrm{G}$ et al (2004) Cellular distribution and function of $\mathrm{P} 2$ receptor subtypes in different systems. Int Rev Cytol 240:31-304. https://doi.org/10.1016/S0074-7696(04)40002-3

73. Atkinson B et al (2006) Ecto-nucleotidases of the CD39/NTPDase family modulate platelet activation and thrombus formation: potential as therapeutic targets. Blood Cells Mol Dis 36:217-222. https://doi.org/10.1016/j.bcmd.2005.12.025

74. Burnstock G, Verkhratsky A (2012). Purinergic signalling and the nervous system. https://doi.org/10.1007/978-3-642-28863-0

75. Visovatti SH et al (2012) Increased CD39 nucleotidase activity on microparticles from patients with idiopathic pulmonary arterial hypertension. PLoS ONE 7:408-429. https://doi.org/10. 1371/journal.pone.0040829

76. Dos Anjos F et al (2020) Potential therapeutic role of purinergic receptors in cardiovascular disease mediated by SARS-CoV-2. J Immunol Res 1-14:2020. https://doi.org/10.1155/2020/8632048

77. Burnstock G (2006) Purinergic signalling - an overview. Novartis Found Symp 276:26-48 
78. Burnstock G (2007) Physiology and pathophysiology of purinergic neurotransmission. Physiol Rev 87(2):659-797. https://doi. org/10.1152/physrev.00043.2006

79. Burnstock G, Knight GE, Greig AVH (2012) Purinergic signaling in healthy and diseased skin. J Investig Dermatol 132:526-546. https://doi.org/10.1038/jid.2011.344

80. Leal, D. B. R. et al. Characterization of NTPDase (NTPDase1; ectoapyrase; ecto- diphosphohydrolase; CD39; EC 3.6.1.5) activity in human lymphocytes. Biochimica et Biophysica Acta - General Subjects, 1721(1-3)9-15, 2005. https://doi.org/10. 1016/j.bbagen.2004.09.006.

81. Burnstock, G. Purine and purinergic receptors. Brain and Neuroscience Advances, 2: 239821281881749, jan. 2018. https:// doi.org/10.1177/2398212818817494.

82. Di Virgilio F (2012) Purines, purinergic receptors, and cancer. Can Res 72(21):5441-5447. https://doi.org/10.1158/00085472.CAN-12-1600

83. Pfaffenzeller MS, Franciosi MLM, Cardoso AM (2020) Purinergic signaling and tumor microenvironment in cervical cancer. Purinergic Signalling 16(1):123-135. https://doi.org/ 10.1007/s11302-020-09693-3

84. Yegutkin, G. G. Nucleotide-and nucleoside-converting ectoenzymes: important modulators of purinergic signalling cascade. Biochimica et Biophysica Acta (BBA) - Molecular Cell Research, 1783:673-694, 2008. https://doi.org/10.1016/j. bbamcr.2008.01.024.

85. Zimmerman $\mathrm{H}$ et al (2007) Ectonucleotidases, molecular properties and functional impact. An R Acad Nac Farm 73:537-566

86. Bagatini MD et al (2018) The impact of purinergic system enzymes on noncommunicable, neurological, and degenerative diseases. J Immunol Res 1-21:2018. https://doi.org/10.1155/ 2018/4892473

87. Burnstock G, Di Virgilio F (2013) Purinergic signalling and cancer. Purinergic Signalling 9(4):491-540. https://doi.org/10. 1007/s11302-013-9372-5

88. Xie R et al (2014) The P2Y2 nucleotide receptor mediates the proliferation and migration of human hepatocellular carcinoma cells induced by ATP. J Biol Chem 289:19137-19149. https:// doi.org/10.1074/jbc.M113.540047

89. Joo, Y. N.; et al. P2Y2R activation by nucleotides released from the highly metastatic breast cancer cell MDA-MB-231 contributes to pre-metastatic niche formation by mediating lysyl oxidase secretion, collagen crosslinking, and monocyte recruitment. Oncotarget 2014; 5: 9322-9334. https://doi.org/ 10.18632/oncotarget.2427.

90. Aliagas E, Vidal A, Texido L, Ponce J, Condom E, MartinSatue M (2014) High expression of ecto-nucleotidases CD39 and CD73 in human endometrial tumors. Mediators Inflamm 2014:509027. https://doi.org/10.1155/2014/509027

91. Cappellari AR et al (2012) Characterization of ectonucleotidases in human medulloblastoma cell lines: ecto-5'NT/ CD73 in metastasis as potential prognostic factor. PLoS ONE 7:e47468. https://doi.org/10.1371/journal.pone.0047468

92. Di Virgilio F, Adinolfi E (2017) Extracellular purines, purinergic receptors and tumor growth. Oncogene 36(3):293-303. https://doi.org/10.1038/onc.2016.206

93. Longhi MS et al (2013) Biological functions of ecto-enzymes in regulating extracellular adenosine levels in neoplastic and inflammatory disease states. J Mol Med (Berl) 91:165-172. https://doi.org/10.1007/s00109-012-0991-z

94. Zanini, D. et al. Ectoenzymes and cholinesterase activity and biomarkers of oxidative stress in patients with lung cancer. Molecular and Cellular Biochemistry, 374(1-2)137-2013. https://doi.org/10.1007/s11010-012-1513-6.

95. Zanini, D. et al. ADA activity is decreased in lymphocytes from patients with advanced stage of lung cancer.
Medical Oncology, 36(9)78, 2019. https://doi.org/10.1007/ s12032-019-1301-1.

96. Ledderose $\mathrm{C}$ et al (2016) Cutting off the power: inhibition of leukemia cell growth by pausing basal ATP release and P2X receptor signaling? Purinergic Signaling 12(3):439-451. https:// doi.org/10.1007/s11302-016-9510-y

97. Mânica A et al (2019) The signaling effects of ATP on melanoma-like skin cancer. Cell Signal 59:122-130. https://doi.org/ 10.1016/j.cellsig.2019.03.021

98. Hu L-P et al (2019) Targeting purinergic receptor P2Y2 prevents the growth of pancreatic ductal adenocarcinoma by inhibiting cancer cell glycolysis. Clin Cancer Res 25(4):13181330. https://doi.org/10.1158/1078-0432.CCR-18-2297

99. Zhang Y et al (2019) Highly-expressed P2X7 receptor promotes growth and metastasis of human HOS/MNNG osteosarcoma cells via PI3K/Akt/GSK3 $\beta / \beta$-catenin and mTOR/HIF1 $\alpha /$ VEGF signaling. Int J Cancer 1068-1082. https://doi.org/10. 1002/ijc. 32207

100. Hevia MJ et al (2019) Differential effects of purinergic signaling in gastric cancer-derived cells through $\mathrm{P} 2 \mathrm{Y}$ and $\mathrm{P} 2 \mathrm{X}$ receptors. Front Pharmacol 10:612. https://doi.org/10.3389/fphar. 2019.00612

101. Burnstock G (2011) Introductory overview of purinergic signalling. Front Biosci E3(3):896-900. https://doi.org/10.2741/ e298

102. Burnstock, G. Short- and long-term (trophic) purinergic signalling. Philosophical Transactions of the Royal Society B: Biological Sciences, 371(1700)20150422, 2016. https://doi. org/10.1098/rstb.2015.0422.

103. Stagg J, Smyth MJ (2010) Extracellular adenosine triphosphate and adenosine in cancer. Oncogene 29(39):5346-5358. https:// doi.org/10.1038/onc.2010.292

104. Burnstock G (2015) Blood cells: an historical account of the roles of purinergic signalling. Purinergic Signalling 11(4):411434. https://doi.org/10.1007/s11302-015-9462-7

105. Cekic C, Linden J (2016) Purinergic regulation of the immune system. Nat Rev Immunol 16(3):177-192. https://doi.org/10. 1038/nri.2016.4

106. Ghiringhelli $F$ et al (2009) Activation of the NLRP3 inflammasome in dendritic cells induces IL-1 $\beta$-dependent adaptive immunity against tumors. Nat Med 15(10):1170-1178. https:// doi.org/10.1038/nm.2028

107. Bian S et al (2013) P2X7 integrates PI3K/AKT and AMPKPRAS40-mTOR signaling pathways to mediate tumor cell death. PLoS ONE 8:60184. https://doi.org/10.1371/journal. pone. 0060184

108. Antonioli L et al (2014) Adenosine pathway and cancer: where do we go from here? Expert Opin Ther Targets 18:973-977. https://doi.org/10.1517/14728222.2014.925883

109. Manica A et al (2018) High levels of extracellular ATP lead to chronic inflammatory response in melanoma patients. J Cell Biochem 119(5):3980-3988. https://doi.org/10.1002/jcb.26551

110. White $\mathrm{N}$ et al (2005) P2Y purinergic receptors regulate the growth of human melanomas. Cancer Lett 224(1):81-91. https://doi.org/10.1016/j.canlet.2004.11.027

111. Gebremeskel S et al (2015) The reversible P2Y12 inhibitor ticagrelor inhibits metastasis and improves survival in mouse models of cancer: P2Y12 Inhibitor Ticagrelor Inhibits Metastasis. Int J Cancer 136(1):234-240. https://doi.org/10.1002/ijc. 28947

112. Ruzsnavszky O et al (2011) UV-B induced alteration in purinergic receptors and signaling on $\mathrm{HaCaT}$ keratinocytes. J Photochem Photobiol, B 105(1):113-118. https://doi.org/10.1016/j. jphotobiol.2011.07.009

113. Merighi S et al (2002) Adenosine receptors as mediators of both cell proliferation and cell death of cultured human melanoma 
cells. J Investig Dermatol 119(4):923-933. https://doi.org/10. 1046/j.1523-1747.2002.00111.x

114. Cekic C et al (2014) Myeloid expression of adenosine $A_{2 A}$ receptor suppresses T and NK cell responses in the solid tumor microenvironment. Can Res 74(24):7250-7259. https://doi.org/ 10.1158/0008-5472.CAN-13-3583

115. Fishman, P. et al. A3 adenosine receptor as a target for cancer therapy: Anti-Cancer Drugs, 13(5)437-443, 2002. https://doi. org/10.1097/00001813-200206000-00001.

116. Koszałka, P. et al. Specific activation of A3, A2A and A1 adenosine receptors in CD73-knockout mice affects B16F10 melanoma growth, neovascularization, angiogenesis and macrophage infiltration. PLOS ONE, 11(3)e0151420, 2016. https://doi.org/10. 1371/journal.pone.0151420.

117. Jiang, T. et al. Comprehensive evaluation of NT5E/CD73 expression and its prognostic significance in distinct types of cancers. BMC Cancer, 18(1)267, 2018. https://doi.org/10.1186/ s12885-018-4073-7.

118. Sadej R, Spychala J, Skladanowski AC (2006) Expression of ecto-5'-nucleotidase (eN, CD73) in cell lines from various stages of human melanoma. Melanoma Res 16(3):213-222. https://doi. org/10.1097/01.cmr.0000215030.69823.11

119. Monteiro, I. et al. CD73 expression and clinical significance in human metastatic melanoma. Oncotarget, 9(42)26659-26669, 2018. https://doi.org/10.18632/oncotarget.25426.

120. Forte $\mathrm{G}$ et al (2012) Inhibition of CD73 improves B cell-mediated anti-tumor immunity in a mouse model of melanoma. J Immunol 189(5):2226-2233. https://doi.org/10.4049/jimmunol.1200744

121. Sadej R, Skladanowski AC (2012) Dual, enzymatic and nonenzymatic, function of ecto-5'-nucleotidase (eN, CD73) in migration and invasion of A375 melanoma cells. Acta Biochim Pol 59(4):647-652

122. Aung TN et al (2017) Understanding the effectiveness of natural compound mixtures in cancer through their molecular mode of action. Int J Mol Sci 18(3). https://doi.org/10.3390/ijms180306 56

123. Noel B et al (2020) Role of natural compounds in preventing and treating breast cancer. Front Biosci (Schol Ed) 12:137-160

124. Ouyang, L. et al. Plant natural products: from traditional compounds to new emerging drugs in cancer therapy. Cell Proliferation, 47(6)506, 2014. https://doi.org/10.1111/cpr.12143.

125. Muller AG et al (2019) Delivery of natural phenolic compounds for the potential treatment of lung cancer. DARU Journal of Pharmaceutical Sciences 27(1):433-449. https://doi.org/10.1007/ s40199-019-00267-2

126. Luo YA et al (2020) Anticancer effects of rosmarinic acid in human oral cancer cells is mediated via endoplasmic reticulum stress, apoptosis, G2/M cell cycle arrest and inhibition of cell migration. JBUON 25(2):1245-1250

127. Radziejewska I, Supruniuk K, Bielawska A (2021) Anti-cancer effect of combined action of anti-MUC1 and rosmarinic acid in AGS gastric cancer cells. Eur J Pharmacol 902. https://doi.org/ 10.1016/j.ejphar.2021.174119

128. Nunes $\mathrm{S}$ et al (2017) Therapeutic and nutraceutical potential of rosmarinic acid-cytoprotective properties and pharmacokinetic profile. Crit Rev Food Sci Nutr 57(9):1799-1806. https://doi.org/ 10.1080/10408398.2015.1006768

129. Pramanik KC et al (2013) Caffeic acid phenethyl ester suppresses melanoma tumor growth by inhibiting PI3K/AKT/XIAP pathway. Carcinogenesis 34(9):2061-2070. https://doi.org/10.1093/ carcin/bgt154

130. Karthikkumar V et al (2015) Rosmarinic acid inhibits DMHinduced cell proliferation in experimental rats. J Basic Clin Physiol Pharmacol 26(2). https://doi.org/10.1515/jbcpp-2014-0044.

131. Yang $\mathrm{K}$ et al (2020) Rosmarinic acid inhibits migration, invasion, and p38/AP-1 signaling via miR-1225-5p in colorectal cancer cells. J Recept Signal Transduct 1-10. https://doi.org/10.1080/ 10799893.2020.1808674

132. Brewer MS (2011) Natural antioxidants: sources, compounds, mechanisms of action, and potential applications. Compr Rev Food Sci Food Saf 10(4):221-247. https://doi.org/10.1111/j. 1541-4337.2011.00156.x

133. Elufioye, T. O.; Habtemariam, S. Hepatoprotective effects of rosmarinic acid: Insight into its mechanisms of action. Biomedicine $\&$ Pharmacotherapy $=$ Biomedecine $\&$ Pharmacotherapie, 112,:108600, https://doi.org/10.1016/j.biopha.2019.108600.

134. Pubchem. National Center for Biotechnology Information. Chemical information about rosmarinic acid (RA). Available in: https://pubchem.ncbi.nlm.nih.gov. Accessed May. 2021

135. Fialová S. et al (2019) Derivatization of rosmarinic acid enhances its in vitro antitumor, antimicrobial and antiprotozoal properties. Molecules, 24(6). https://doi.org/10.3390/molecules24061078

136. Petersen M (2013) Rosmarinic acid: new aspects. Phytochem Rev 12(1):207-227. https://doi.org/10.1007/s11101-013-9282-8

137. Hitle M. et al (2020) Rosmarinic acid-human pharmacokinetics and health benefits. Planta Med a-1301-8648,. https://doi.org/ 10.1055/a-1301-8648

138. Luo C et al (2020) A review of the anti-inflammatory effects of rosmarinic acid on inflammatory diseases. Front Pharmacol 11. https://doi.org/10.3389/fphar.2020.00153

139. Yahfoufi N. et al (2018) The immunomodulatory and anti-inflammatory role of polyphenols. Nutrients, 10(11). https://doi.org/10. 3390/nu10111618

140. Jang, Y. G.; Hwang, K. A.; Choi, K. C. Rosmarinic acid, a component of rosemary tea, induced the cell cycle arrest and apoptosis through modulation of HDAC2 expression in prostate cancer cell lines. Nutrients, 10(11)1784, 2018. https://doi.org/10.3390/ nu10111784.

141. Han YH, Kee JY, Hong SH (2018) Rosmarinic acid activates AMPK to inhibit metastasis of colorectal cancer. Front Pharmacol 9:68. https://doi.org/10.3389/fphar.2018.00068

142. Ozturk H et al (2014) Protective effects of rosmarinic acid against renal ischaemia/reperfusion injury in rats. J Pak Med Assoc 64(3):260-265

143. Sevgi K, Tepe B, Sarikurkcu C (2015) Antioxidant and DNA damage protection potentials of selected phenolic acids. Food and Chemical Toxicology: An International Journal Published for the British Industrial Biological Research Association 77:12-21. https://doi.org/10.1016/j.fct.2014.12.006

144. Swarup V et al (2007) Antiviral and anti-inflammatory effects of rosmarinic acid in an experimental murine model of Japanese encephalitis. Antimicrob Agents Chemother 51(9):3367-3370. https://doi.org/10.1128/AAC.00041-07

145. Wei $Y$ et al (2018) Rosmarinic acid mitigates lipopolysaccharideinduced neuroinflammatory responses through the inhibition of TLR4 and CD14 expression and NF- $\mathrm{KB}$ and NLRP3 inflammasome activation. Inflammation 41(2):732-740. https://doi.org/ 10.1007/s10753-017-0728-9

146. Lembo $\mathrm{S}$ et al (2014) The modulatory effect of ellagic acid and rosmarinic acid on ultraviolet-B-induced cytokine/chemokine gene expression in skin keratinocyte $(\mathrm{HaCaT})$ cells. Biomed Res Int 1-8:2014. https://doi.org/10.1155/2014/346793

147. Rocha $\mathbf{J}$ et al (2015) Anti-inflammatory effect of rosmarinic acid and an extract of Rosmarinus officinalis in rat models of local and systemic inflammation. Basic Clin Pharmacol Toxicol 116(5):398-413. https://doi.org/10.1111/bcpt.12335

148. Friedman, T. The Effect of rosmarinic acid on immunological and neurological systems: a basic science and clinical review. Journal of Restorative Medicine, 4(1)50-59, 2015. https://doi. org/10.14200/jrm.2015.4.0105.

149. Marinho, S. et al. Anti-inflammatory effects of rosmarinic acid-loaded nanovesicles in acute colitis through modulation of 
NLRP3 inflammasome. Biomolecules, 11(2)162, 26 Jan. 2021. https://doi.org/10.3390/biom11020162.

150. Han $Y$ et al (2019) Rosmarinic inhibits cell proliferation, invasion and migration via up-regulating miR-506 and suppressing MMP2/16 expression in pancreatic cancer. Biomed Pharmacother 115:108878. https://doi.org/10.1016/j.biopha.2019.108878

151. Cao W et al (2016) Rosmarinic acid inhibits inflammation and angiogenesis of hepatocellular carcinoma by suppression of NF- $\mathrm{BB}$ signaling in H22 tumor-bearing mice. J Pharmacol Sci 132(2):131-137. https://doi.org/10.1016/j.jphs.2016.09.003

152. Oğuz A et al (2020) Investigation of antioxidant effects of rosmarinic acid on liver, lung and kidney in rats: a biochemical and histopathological study. Folia Morphol 79(2):288-295. https:// doi.org/10.5603/FM.a2019.0087

153. Olivares, A. et al. Effect of rosmarinic acid and ionizing radiation on glutathione in melanoma B16F10 cells: a translational opportunity. Antioxidants, 9(12)1291, 2020. https://doi.org/10. 3390/antiox9121291.

154. Xu Y et al (2010) Anti-invasion effect of rosmarinic acid via the extracellular signal-regulated kinase and oxidation-reduction pathway in Ls174-T cells. J Cell Biochem 111(2):370-379. https://doi.org/10.1002/jcb.22708

155. Zou J et al (2018) Discovery of a novel ERp57 inhibitor as antiplatelet agent from Danshen (Salvia miltiorrhiza). EvidenceBased Complementary and Alternative Medicine 1-9:2018. https://doi.org/10.1155/2018/9387568

156. Heidary Arash, E. et al. MARK4 inhibits Hippo signaling to promote proliferation and migration of breast cancer cells. EMBO reports, 18(3)420-436, 2017. https://doi.org/10.15252/embr. 201642455.

157. Liu, Z. et al. Mark4 promotes oxidative stress and inflammation via binding to PPAR $\gamma$ and activating NF- $\mathrm{KB}$ pathway in mice adipocytes. Scientific Reports, 6(1)21382, 2016. https://doi.org/ 10.1038/srep21382.

158. Helenius, M.; Jalkanen, S.; Yegutkin, G. G. Enzyme-coupled assays for simultaneous detection of nanomolar ATP, ADP, AMP, adenosine, inosine and pyrophosphate concentrations in extracellular fluids. Biochimica et Biophysica Acta (BBA) - Molecular Cell Research, 1823 (10)1967-1975, 2012. https://doi.org/10. 1016/j.bbamcr.2012.08.001.

159. Mcallister SS, Weinberg RA (2010) Tumor-host interactions: a far-reaching relationship. J Clin Oncol 28(26):4022-4028. https://doi.org/10.1200/JCO.2010.28.4257

160. Munn, D. H.; BRONTE, V. Immune suppressive mechanisms in the tumor microenvironment. Current Opinion in Immunology, 39:1-6, 2016. https://doi.org/10.1016/j.coi.2015.10.009.

161. Allard B et al (2017) The ectonucleotidases CD39 and CD73: novel checkpoint inhibitor targets. Immunol Rev 276(1):121144. https://doi.org/10.1111/imr.12528

162. Sawayama $\mathrm{H}$ et al (2014) Clinical impact of the Warburg effect in gastrointestinal cancer (Review). Int J Oncol 45(4):1345-1354. https://doi.org/10.3892/ijo.2014.2563

163. Campos-Contreras, A. Del R.; Díaz-Muñoz, M.; Vázquez-Cuevas, F. G (2020) Purinergic signaling in the hallmarks of cancer. Cells, 9(7). https://doi.org/10.3390/cells9071612
164. FENG, L. et al. Vascular CD39/ENTPD1 directly promotes tumor cell growth by scavenging extracellular adenosine triphosphate. Neoplasia, 13(3)206-IN2, 2011. https://doi.org/10.1593/ neo.101332.

165. OHSHIMA, Y. et al. $\gamma$-Irradiation induces $\mathrm{P} 2 \mathrm{X} 7$ receptordependent ATP release from B16 melanoma cells. Biochimica et Biophysica Acta (BBA) - General Subjects, 1800(1)40-46, 2010. https://doi.org/10.1016/j.bbagen.2009.10.008.

166. Adinolfi E et al (2018) The P2X7 receptor: a main player in inflammation. Biochem Pharmacol 151:234-244. https://doi.org/ 10.1016/j.bcp.2017.12.021

167. De Marchi, E. et al. P2X7 Receptor as a therapeutic target. In: Advances in Protein Chemistry and Structural Biology. Elsevier, 2016. 104:39-79. https://doi.org/10.1016/bs.apcsb.2015.11.004.

168. Han S, Yang S et al (2015) Anti-Warburg effect of rosmarinic acid via miR-155 in gastric cancer cells. Drug Design, Dev Ther 2695. https://doi.org/10.2147/DDDT.S82342

169. Korybalska, K. et al. The role of purinergic P2Y12 receptor blockers on the angiogenic properties of endothelial cells: an in vitro study. Journal of Physiology and Pharmacology, 2018. https://doi.org/10.26402/jpp.2018.4.06.

170. Cho MS et al (2017) Role of ADP receptors on platelets in the growth of ovarian cancer. Blood 130(10):1235-1242. https://doi. org/10.1182/blood-2017-02-769893

171. Bellefeuille SD, Molle CM, Gendron F-P (2019) Reviewing the role of $\mathrm{P} 2 \mathrm{Y}$ receptors in specific gastrointestinal cancers. Purinergic Signalling 15(4):451-463. https://doi.org/10.1007/ s11302-019-09678-x

172. Hemminki O, Dos Santos JM, Hemminki A (2020) Oncolytic viruses for cancer immunotherapy. J Hematol Oncol 13. https:// doi.org/10.1186/s13045-020-00922-1

173. Ballerini $\mathrm{P}$ et al (2018) P2Y12 receptors in tumorigenesis and metastasis. Front Pharmacol 9:66. https://doi.org/10.3389/fphar. 2018.00066

174. Gershenwald, J. E.; Scolyer, R. A. Melanoma staging: American Joint Committee on Cancer (AJCC) 8th Edition and Beyond. Annals of Surgical Oncology, 25(8)2105-2110, 2018. https:// doi.org/10.1245/s10434-018-6513-7.

175. Waer, C. N. et al. Rosmarinic acid/ blue light combination treatment inhibits head and neck squamous cell carcinoma in vitro. Anticancer Research, 40(2)751-758, 2020. https://doi.org/10. 21873/anticanres.14006.

176. Ozgun G, Ozgun E (2019) The cytotoxic concentration of rosmarinic acid increases MG132-induced cytotoxicity, proteasome inhibition, autophagy, cellular stresses, and apoptosis in HepG2 cells. Hum Exp Toxicol 39(4):514-523. https://doi.org/10.1177/ 0960327119896614

Publisher's Note Springer Nature remains neutral with regard to jurisdictional claims in published maps and institutional affiliations. 